\title{
CRECIMIENTO Y POLÍTICA TERRITORIAL EN LAS ISLAS BALEARES (1955-2000)
}

POR

\author{
ONOFRE RULLAN
}

En las Islas Baleares, después de más de cuarenta años de crecimiento y desarrollo turístico, el urbanismo, el turismo, el territorio, la conservación y gestión de espacios naturales, la política inmobiliaria, etc. resultan, difícilmente desligables para ser analizados separadamente.

En los escasos $5.014 \mathrm{~km}^{2}$ del archipiélago se concentra una hacinada actividad turística y urbanística, un denso magma inmobiliario que impregna todo el escenario geográfico. Hoy empiezan a confundirse conceptualmente términos como turismo, urbanismo y actividad inmobiliaria y, de seguir la tendencia, tales vocablos pronto serán intercambiables con la propia denominación Islas Baleares.

El presente artículo pretende analizar el proceso mediante el cual se ha llegado a la situación actual. A partir de ahí se pretende entrever el escenario geográfico que se está construyendo para principios de siglo y de milenio.

\section{Evolución general del proceso}

La saturación territorial que viven hoy las Islas Baleares es el efecto del crecimiento económico experimentado por el archipiélago en la

Onofre Rullán, Profesor de Análisis Geográfico Regional de la Universidad de las Islas Baleares.

Estudios Geográficos

Tomo LX, n. ${ }^{\circ} 236$, julio-septiembre 1999 
segunda mitad del siglo xx. En el fondo de tal crecimiento está, no vale la pena repetirlo, el sector turístico y sus impactos sobre los sectores de la construcción e inmobiliario ${ }^{1}$.

El proceso de turistización de las Islas Baleares despega en la década de los años 50 y se inserta en el contexto de la nueva división internacional de funciones económicas que se instaurará después de la segunda guerra mundial. El crecimiento de las economías norteamericana y europea posibilitará su expansión incluso sobre territorios que, como el español, eran considerados políticamente impíos.

El reconocimiento del régimen franquista por parte de la ONU en 1951 abrirá el camino de las relaciones del régimen autárquico español con las economías liberales europeas. El Plan de Estabilización de 1959 será el lubricante necesario para expandir, hacia el sur, la pujante frontera económica europea. En este contexto el turismo jugará el clásico papel de exportación desde el sur hacia el norte, de la periferia hacia el centro. Una nueva relación norte-sur que, en este caso, coincide económica y geográficamente.

Las Islas Baleares se incorporan plenamente a este proceso y así, en 1955 , los servicios turísticos prestados alcanzan ya el $50 \%$ del valor de todas las exportaciones. De esta manera, justo en la mitad de los 50, equidistante entre el reconocimiento de la ONU (1951 y el Plan de Estabilización (1959), el archipiélago Balear despega en el que será el proceso de crecimiento económico y territorial más importante de su historia. El turismo creará la nueva urbanización, la urbanización creará el nuevo territorio; el turismo será el motor del urbanismo y el urbanismo el del territorio.

Justo en el límite del cambio de siglo y de milenio, cuarenta y cinco años después de aquel despegue, parece que acaba la primera etapa y, con importantes matices según las opciones políticas, se está planteando la limitación al crecimiento turístico y, en mucho menor grado, el urbanístico. La Ley General Turística y las Directrices de Ordenación Territorial sitúan cronológicamente en 1999 este primer fin de etapa.

1 Todos los estudios económicos tienen perfectamente calibrado el peso y función del sector turístico sobre la economía balear. Véase al respecto las más recientes obras sobre la evolución económica de las islas (López Casanovas y Rosselló Villalonga, 1998; Rivero Ceballos y Salvá i Tomás, 1998: 207-222 y especialmente Reig Martínez y Picazo Tadeo, 1998). 
Esta reconducción del proceso se está intentando llevar a cabo en el momento de la efectiva integración de los europeos en el territorio balear, cuando según cifras oficiales los ciudadanos comunitarios ya poseen el $10 \%$ de las unidades urbanas catastrales, cuando de un inicial modelo con función turística dominante frente a la función residencial subsidiaria, se están invirtiendo los términos y la residencialización es cada vez más dominante. El territorio balear se está reestructurando a escala plenamente europea.

¿Qué ha sucedido en esta segunda mitad del siglo xx?, ¿cómo se ha llegado a la situación actual? La Figura 1 muestra el comportamiento de dos indicadores clave - pasajeros contabilizados en los aeropuertos baleares y valor añadido bruto- que, con un coeficiente de correlación del 0,97 , corren en paralelo a oras variables como trabajadores asalariados en el sector de la construcción o consumo de cemento.

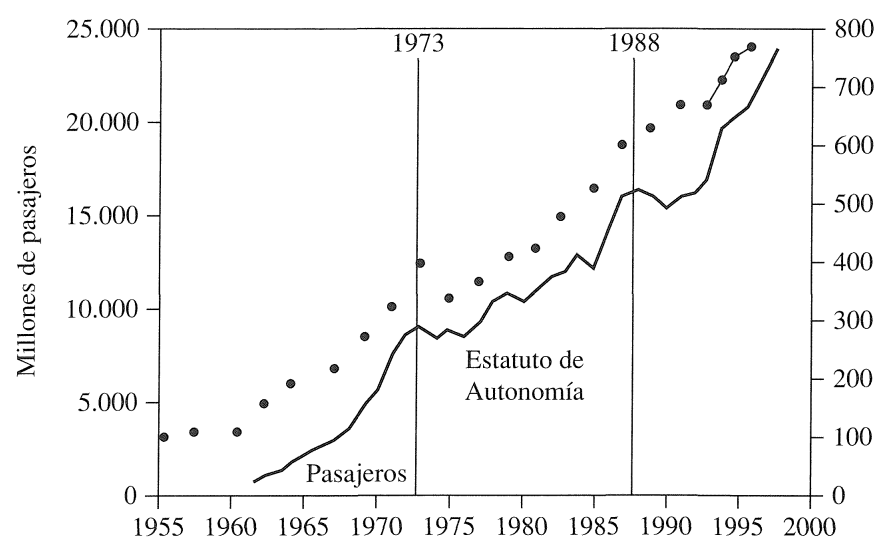

Fuente: Reig-Picazo (1998: 313) y datos AENA

ORS'99

FIG. 1.-Pasajeros aeroportuarios y VAB en las Islas Baleares.

En esta figura pueden identificarse tres fases cuantitativas claramente diferenciadas separadas por los años 1973 y 1988. Tres impulsos de crecimiento turístico e inmobiliario que, a la vez, responden a tres claras fases expansivas de las economías europeas. La primera y la segunda constituyen lo que en su momento se llamó el primer y segundo «boom» turístico, la tercera constituye sin duda el tercer «boom» turístico (Rullan Salamanca, 1997). Todos los indicadores reflejan el movimiento es- 
tructural del territorio balear incluidas, como no, las variables demográficas y turísticas en estos años clave (Cuadro I).

CUAdro I

POBLACIÓN Y TURISMO EN LAS ISLAS BALEARES

EN LOS TRES IMPULSOS DE CRECIMIENTO

\begin{tabular}{lcccr}
\hline & $\begin{array}{c}\text { Población } \\
\text { residente }\end{array}$ & $\begin{array}{c}\text { Plazas } \\
\text { turísticas }\end{array}$ & $\begin{array}{c}\text { Turistas } \\
\text { (miles) }\end{array}$ & Estancias \\
\hline 1955 & 348.805 & 6.022 & 188,7 & 1.521 .751 \\
1973 & 557.434 & 222.680 & $3.573,0$ & 37.543 .466 \\
1988 & 728.173 & 457.056 & $7.044,8$ & 89.398 .640 \\
1997 & $783.293 *$ & 515.454 & $9.302,9$ & 100.284 .895 \\
\hline
\end{tabular}

* Datos de 1998

Fuente: Elaboración propia a partir de (Barceló Pons, 1989: 304 y 306) y de la serie «Evolución Económica» de la Caixa de les Balears.

El crecimiento ha sido muy importante, hasta el punto de alcanzar agregando en momentos punta los turistas no contabilizados por las estadísticas oficiales - un número de población no residente igual a la residente $\mathrm{y}$, en consecuencia, una densidad de hecho superior a 300 hab. $/ \mathrm{km}^{2}$, el doble de la que resulta contabilizando únicamente la población de derecho.

¿Qué políticas urbanísticas y territoriales han acompañado este proceso? Desde el punto de vista del marco institucional en que se han movido las Islas Baleares cabe señalar dos fases separadas por el año 1983. Efectivamente con la aprobación del Estatuto de Autonomía de 1983 se abre un escenario competencial nuevo en cuanto a la responsabilidad de las políticas urbanísticas, territoriales y turísticas de la Comunidad Autónoma de las Islas Baleares (CAIB) ${ }^{2}$.

${ }^{2}$ La Ley Orgánica 2/1983, de 25 de febrero, que aprueba el Estatuto de Autonomía de las Islas Baleares (BOE de 1 de marzo de 1983), atribuye en su artículo 10 la competencia exclusiva a la Comunidad Autónoma, entre otras, en las siguientes materias: Ordenación del territorio, incluido el litoral, urbanismo y vivienda (10.3); Obras públicas en el territorio de la Comunidad Autónoma que no sean de interés general del Estado (10.4); Ferrocarriles, carreteras y caminos (10.5); Régimen de aguas y aprovechamiento hidráulico (10.6); Fomento y promoción del turismo. Ordenación del turismo en su ámbito territorial (10.9); Fomento del desarrollo económico dentro del territorio de la Comunidad Autónoma (10.17). La modificación del estatuto de 1998 no ha introducido variaciones substanciales en relación a las materias territoriales. 
En relación a las pulsaciones de crecimiento antes descritas cabe señalar cómo los dos primeros tercios del proceso (1955-83) correspondientes al primer boom turístico y primera mitad del segundo, fueron abordados desde instrumentos y políticas del gobierno central, coincidiendo con la primera fase de crecimiento y posterior crisis. Con el inicio de la segunda expansión de crecimiento, el año 1983 inaugura la política y la responsabilidad institucional del parlamento y gobierno autónomo. Este último tercio del proceso turistizador ha coincidido con las dos últimas puntas más importantes de crecimiento (1988 y finales de los 90) sólo salpicadas por algunas minicrisis de signo más bien coyuntural.

Como sea que, en territorios de dimensiones reducidas como el balear, los períodos de crecimiento económico se asocian en momentos de fuerte crisis territorial y ambiental, la actual fase autonómica suele percibirse como una época con un cierto cariz esquizofrénico: saludable y próspera económicamente a la vez que enfermiza y decadente ambientalmente. Las disecciones estructuralistas de la realidad geográfica conducen a estas y otras «paradojas».

\section{Crecimiento intensivo y concentrado hasta 1973}

El efecto formal del primer crecimiento turístico. - El crecimiento de los 60 fue urbanísticamente intensivo y territorialmente concentrado. La particular forma de implosión urbana que experimentan las Islas Baleares hasta 1973 tendrán en el hotel y en el bloque de pisos a sus principales «fósiles guía». Hoteles para alojar a los más de 3 millones de turistas que visitarán el archipiélago, bloques de pisos para albergar a los inmigrantes que, desde diferentes puntos de la península, serán absorbidos para la pujante actividad económica que despega. Éxodo rural peninsular para el crecimiento urbano insular.

Ambos fenómenos (hoteles-bloques de pisos y núcleos preexistentes de residentes-urbanizaciones turísticas costeras) no son más que la particular forma de crecimiento intensivo turístico de los 60 que, a la vez, no es más que la versión local de la forma más genérica de crecimiento de la época, tanto a escala española como europea. Un urbanismo, el intensivo de los 60, que adquirirá muy mala fama ante la nueva cultura urbanística de los 80, ésta (...) acusa y ridiculiza al «urbanismo desa- 
rrollista» identificado con el franquismo, bien fuese por calculada intención política o por falta de cultura y de conocimiento histórico, condenando sus grandes previsiones de crecimiento y sus «derroches infraestructurales», como si hubiesen sido producto sólo de la dictadura, y no también de una situación cultural universal. (Terán Troyano, 1996: 179).

Para el caso que nos ocupa tal afirmación es plenamente constatable y, además, explicable. En efecto, si bien hasta 1960 el crecimiento es autofinanciado desde las islas, entre 1960 y 1967-68 serán los operadores turísticos centroeuropeos quienes financien a los hoteleros hasta que, en 1967-68, irrumpa en el sector la banca oficial y privada (Aguiló, Bardolet y Sastre, 1981: 37-41). Si la demanda va siendo cada vez más europea y la infraestructura necesaria se financia desde Europa, el producto no podía ser más que formalmente europeo.

En cualquier caso la verdad es que la irrupción del turismo, y sus consecuencias urbanísticas sobre el territorio y la sociedad preturística, se llevó a cabo de forma improvisada y con muy pocas posibilidades de encauzar la gran inundación de crecimiento que se iba formalizando geográficamente.

La difusión del fenómeno fue diferente según las islas. En Mallorca, la nueva urbanización, que primitivamente había buscado enclaves montañosos, se expande desde la bahía de Palma. Sólo el término municipal de Palma, en 1960, concentraba el 48\% de la oferta, un porcentaje que justo antes de la guerra civil ascendía al 70\% (Aguiló et al., 1981: 16). Por su parte Menorca no se incorporará, de hecho, al crecimiento hotelero hasta el final de la década de los 60 y no será hasta bien entrados los 80 cuando pueda hablarse de una economía menorquina planamente turistizada. Ibiza, sin núcleos rurales concentrados, conocerá la urbanización al mismo tiempo que la turistización, en la mayor de las Pitiusas, si exceptuamos la capital, urbanismo y turismo son términos plenamente equivalentes.

El urbanismo intensivo._Aprobada la Ley del Suelo de 1956 (LS56), sus efectos sobre la planificación municipal fueron más bien indirectos $\mathrm{y}$, en todo caso, se dejaron ver cuando el primer «boom» turístico llegaba ya a su fin.

Antes de 1956 habían sido 26 las urbanizaciones turísticas o residenciales aprobadas (Aguiló y Verger, 1982: 18) al margen de todo plan de alcance municipal que, como es sabido, hasta 1956 no se impuso 
como obligatorio. La gran demanda turística y urbanística generada durante el primer impulso de crecimiento obligó precisamente a los ayuntamientos a promover la aprobación de los correspondientes planes municipales que (...) nacían de la necesidad de contar con dicho instrumento para poder realizar los planes parciales de iniciativa particular. (Aguiló y Verger, 1982: 19).

Los primeros Planes Generales nacen así desde la demanda de urbanización particular más que como consecuencia de la decisión colectiva de planificar. Planes Generales, Planes Generales Sectoriales y Planes Parciales (Aguiló y Verger, 1982: 19-20) invaden la geografía insular con unos dimensionados situados muy por encima de la demanda prevista. Unos dimensionados que, más que listones de crecimiento razonablemente establecidos, reflejaban los deseos de crecimiento económico del planificador urbanístico, como si el plan fuera a tirar de la economía, como si lo dibujado fuera a convertirse en realidad sin más. El establecimiento de dimensionados superficiales y techos edificatorios «inalcanzables» fue la manera de sortear la obligación de imponer límites urbanísticos al crecimiento que establecía la LS56.

De todas maneras, por si no fuera posible la solución urbanística local a la demanda particular, desde 1963 podía salvarse al escollo planificador gracias a la ley de centros y zonas de interés turístico nacional ${ }^{3}$. Esta ley se inscribe en lo que se ha llamado el "progresivo deterioro de la ley del suelo y de la política urbanística» (Terán Troyano, 1982: 44276). Se aplicaría en cuatro ocasiones en la isla de Mallorca, entre 1966 y $1978^{4}$, y en otras cuatro en Menorca, entre 1969 y 1975. Se trató de otra forma de conseguir cobertura legal, sin necesidad de plan municipal previo, que pudo funcionar cuando los mecanismos locales de planeamiento municipal no estaban lo suficientemente ajustados ni convenientemente lubricados.

Este primer crecimiento urbanístico se llevó a cabo con más que notables deficiencias infraestructurales ${ }^{5}$. Prueba de ello es que en 1970 la administración turística, dos años antes del fin del primer impulso de

${ }^{3}$ Ley 19\%/1963, de 28 de diciembre, sobre centros y zonas de Interés Turístico Nacional (BOE de 31 de diciembre de 1963). El reglamento se apruebas mediante el Decreto 4.297/1984, de 23 de diciembre.

4 No contabilizamos la declaración de 1981 de la zona mallorquina de Mondragó ya que en 1982, sin que pudiera ejecutarse, sería derogada.

5 Véase lo que se opinaba al respecto, en 1972, desde importantes sectores de la administración (Terán Troyano, 1982:448-49).

$$
-409-
$$


crecimiento, decretó los requisitos mínimos de infraestructura para alojamientos turísticos ${ }^{6}$ que, como veremos, posteriormente será adaptado y ampliado por la legislación autonómica. Este decreto obliga precisamente a contar con una serie de elementos de marcado carácter urbanístico: agua potable (200 l/hab./día), tratamiento y evacuación de aguas residuales, electricidad ( $1 \mathrm{kw} / \mathrm{plaza}$ ), accesos, aparcamientos, tratamiento y eliminación de basuras. Unos elementos que podrían haber sido resueltos simplemente con una ordenada política urbanística y que precisamente la LS75 hará obligatorios para todo el suelo urbano aunque no los cuantifique. La amenaza de declaración de zona de infraestructura deficiente y la consiguiente no autorización de más alojamientos turísticos, pretendía obligar a la dotación de aquellos elementos de urbanización.

Fuera vía Ley del Suelo, vía declaración de centro y zona de ITN o mediante el decreto de infraestructuras, la verdad es que la primera experiencia de planificación urbanística del crecimiento fue algo caótica y desconcertante para todos los agentes sociales de la época, se trataba de una novedad que no contaba con precedentes ni experiencias. De hecho la «primera finalidad inmediata» que plantea, en 1970, el que será Plan Provincial de Ordenación de Baleares de 1973 es acabar con la «situación de desconcierto y desconocimiento reinante sobre los problemas urbanísticos» (PPOB, 1970: 12).

Conforme a lo dispuesto en el artículo 24 de la LS56, en 1973, se aprobó el Plan Provincial de Ordenación de Baleares ${ }^{7}$ que, justo en el momento en que acababa la primera expansión de crecimiento, venía a desbloquear las aspiraciones de desarrollo para aquellas situaciones que, bien por falta de plan municipal o por falta de declaración de ITN, no podían «crecer». Así el PPOB tenía un carácter subsidiario tanto para situaciones urbanas o de desarrollo urbano ${ }^{8}$ como para el suelo rústi-

${ }^{6}$ Decreto 3.78\%/1970, de 19 de diciembre, sobre requisitos minimos de infraestructura en los alojamientos turísticos (BOE, de 18 de enero de 1971).

${ }^{7}$ Dicho plan había sido aprobado inicialmente el 21 de mayo de 1971, provisionalmente el 28 de enero de 1972 y definitivamente por Orden del Ministerio de la Vivienda de 4 de abril de 1973 (BOE de 8 de mayo de 1973).

${ }_{8}$ Mediante la aprobación previa de unas Normas Subsidiarias de Plan General podían desarrollarse Planes Parciales sin necesidad de Plan General Municipal en aquellas zonas grafiadas como áreas turísticas — prácticamente todo el litoral- o áreas de desarrollo urbano - los contornos periurbanos de los núcleos preexistentes-. Con ello se consolidaba el modelo antes mencionado de desarrollo intensivo y concentrado. Dos años más tarde, la LS75 cerraría la posibilidad de planeamiento parcial sin la previa clasifi- 
$\mathrm{co}^{9}$ dónde se establecerían las primeras medidas, todavía muy tenues, de protección ${ }^{10}$.

Con este escenario de planta hotelera construida, planes municipales expansionistas, enormes déficits infraestructurales, PPOB subsidiario y primeras, aunque leves, medidas de protección urbanística, se llega a la crisis de 1973 que, después de un pequeño parón de crecimiento, recompondrá la oferta y el urbanismo para, unos pocos años más tarde, retomar el crecimiento.

\section{Crecimiento y extensificación en los años 80}

Los nuevos productos turísticos. - La crisis del petróleo de 1973 recompone y transforma el turismo y el urbanismo balear. Se frena el crecimiento hotelero ${ }^{11} \mathrm{y}$ se acelera el extrahotelero, primero de apartamentos y más tarde de chalets. Si el hotel y el bloque de pisos constituye el fósil guía del primer boom turístico, el apartamento y el adosado es el que caracteriza el segundo. La extensificación del crecimiento se lleva a cabo gracias a la generalización de estos dos tipos de oferta que, ahora, alcanzarán grandes cotas de desarrollo.

cación por parte del planeamiento municipal, con ello ya no eran posibles las antiguas Normas Subsidiarias de Plan General sino las nuevas que, como es sabido, al clasificar como Suelo Apto para la Urbanización, ya serán completamente equiparables a un Plan General de Ordenación Urbana de la ley modificada.

${ }^{9}$ En la zonificación de excedente, en suelo rústico, se admitían las llamadas Ordenaciones Especiales para desarrollos de baja densidad (20 hab./Ha) que consistían, de hecho, en zonas de transformación urbana mediante Plan Parcial previa su delimitación por el planeamiento municipal.

${ }_{10}$ Quizás sea necesario anotar el Decreto 984/1972, de 24 de marzo, por el que se declara Paraje Pintoresco la costa noroeste de la isla de Mallorca (Baleares), (BOE de 19 de abril de 1972) al amparo de lo dispuesto en la antigua legislación de Patrimonio (1933). Se trata de la primera actuación protectora dictada aunque fuera desde la política de Patrimonio y no desde la urbanística. La Ley 15/1975, de 2 de mayo, de Espacios Naturales Protegidos encomienda la conversión de los antiguos Parajes Pintorescos a alguna de las figuras que ella misma prevé. En cualquier caso con la Ley 16/1985, de 25 de junio, de Patrimonio Histórico Español, todos los parajes pintorescos se convertían automáticamente en Bienes de Interés Cultural (BIC).

${ }^{11}$ Los hoteles que cierran serán los más pequeños y de menor categoría y, aun así, hay que relativizar bastante lo que supuso el parón del 73. Basta señalar como entre 1972 y 1979 se dan de baja anualmente unas 1.600 plazas hoteleras correspondientes a unos 35 hoteles, destacando 1973 con 55 hoteles dados de baja (3.368 plazas) (Aguiló et al., 1981:10, 20 y 22). Unas cifras que hay que poner en relación al parque de más de 230.000 plazas de esta época, listón del que no se baja al compensar las bajas con la concentración en hoteles de mayor capacidad. 
De hecho las estadísticas oficiales tardarán varios años en contabilizar la oferta extrahotelera con las mínimas garantías de fiabilidad. Los primeros recuentos de este tipo de oferta datan de $1979^{12}$ que serán corregidos al año siguiente. Efectivamente, la corrección de los datos de 1979 llevó a la contabilización de una oferta real, legal o no, de más de 500.000 plazas para 1980. El Cuadro II resume los datos de 1980.

CUADRo II

OFERTA TOTAL DE ALOJAMIENTO

EN LAS ISLAS BALEARES EN 1980

\begin{tabular}{lrc}
\hline Tipología & Plazas & Porcentaje \\
\hline Hoteles & 212.185 & 41 \\
Apartamentos & 186.888 & 36 \\
Chalets & 112.428 & 22 \\
Otros turísticos & 3.851 & 1 \\
\cline { 2 - 3 } TotaL & 521.428 & 100 \\
\hline
\end{tabular}

Fuente: Elaboración propia a partir de (Aguiló et al. 1981: 61-64).

Sin embargo al contrastar tales datos con la demanda turística contabilizada en puertos y aeropuertos se detecta cómo dos tercios de la oferta de apartamentos y la práctica totalidad de la de chalets correspondía a residentes y no a turistas (Aguiló et al., 1981: 94-95). Este hecho es una de las grandes novedades de los 80: la notable expansión de segundas residencias de la población autóctona en forma de chalets y apartamentos como consecuencia de aumento de renta local. El crecimiento turístico daba sus primeros frutos indirectos y la nueva urbanización iría destinada preferentemente a satisfacer la emergente demanda local.

De hecho, en 1979, los turistas se alojaban en un $79 \%$ en hoteles y en un $19 \%$ en apartamentos, una diferencia con clara tendencia a amino-

12 Se trata de un estudio realizado por Maver Consult para lo que debía haber sido el primer Plan de Ordenación de la Oferta Turística. El recuento da la cifra de 137.661 plazas de apartamentos de las que tan solo cerca del 20\% estaban legalizadas (Evolución Económica, 1989:168).

$$
-412-
$$


rarse como lo demostrará el hecho que tal relación fuera de 57\% a 34\% en 1989 (Albertí Sastre, 1995: 79) y en la actualidad ambas tasas se encuentren muy cerca de la equiparación.

Entre las razones que comúnmente se alegan para explicar este viraje de la oferta balear de alojamiento destacan un supuesto cambio en los gustos de la demanda así como un menor coste de construcción menos servicios generales - y de explotación — menos personal- de los apartamentos frente a los hoteles. Sin cuestionar la importancia de tales factores en el cambio en la composición de la oferta quizás pueda relacionarse el cambio con la fuerte irrupción del sector inmobiliario.

Si bien no es descartable que, en un primer momento de la crisis del 73 , hubiera algún tipo de clandestinización de la oferta antes hotelera en apartamental, en los años 80 será el despliegue inmobiliario no estrictamente turístico el responsable del tirón de reconversión y crecimiento extrahotelero. Ante este panorama la apetencia de los inversores virará hacia el sector inmobiliario al ofrecer éste una expectativa de beneficios rápidos muy superiores a los que la inversión estrictamente turística impone con sus lentos procesos de amortización.

En cualquier caso la década de los 80 será la de las Asociaciones y Cadenas Hoteleras, capaces incluso de dar el salto a otros destinos turístico extrainsulares, quienes suplantarán al antiguo hotelero individual del primer boom turístico.

La décadas de los 80 fue nuevamente de fuerte crecimiento económico. La figura 2 muestra el consumo de cemento y el visado oficial de viviendas en la comunidad. Tales variables nos marcan nuevamente la segunda y tercera pulsación de crecimiento acaecidas desde finales de los 70. Vale la pena notar cómo es precisamente en este momento cuando Menorca se incorpora definitivamente al modelo turístico balear. Razón a la cual debemos acudir para explicar la horizontalidad actual del paisaje urbanístico menorquín. Menorca es, también urbanísticamente, la de menores alturas del archipiélago.

El proceso de residencialización iniciado en los 80 no es, evidentemente, un fenómeno estrictamente local. El crecimiento en el número de viviendas en el quinquenio 85-90, a escala española, fue espectacular (Fernández Durán, 1993: 213). Sólo en la franja costera alicantina, entre 1985 y 1989, aflorarán 70.000 nuevas viviendas (Vera Rebollo, 1990: 50). 
Los primeros intentos de actuar sobre la galopante urbanización.-Las actuaciones autonómicas sobre este nuevo escenario se materializarán, como dijimos, a partir de $1983{ }^{13}$. ¿En qué situación se encontraba entonces la CAIB? En 1979 los primeros ayuntamientos democráticos carecían de planeamiento (29 de los 65 municipios) o, en el mejor de los casos, contaban con planeamientos generados en la época expansiva del primer boom turístico ${ }^{14}$. Ante éste panorama el crecimiento de los 80 no encontraría ninguna traba, menos aún que el de los 60, pues mientras éste necesitó de la aprobación de los correspondientes planes municipales para desarrollar las urbanizaciones particulares, el crecimiento de los 80 ya contaba con planes que daban pista libre al desarrollo del segundo boom. Los municipios, en 1981, tenían un techo construido en urbano y urbanizable ordenado (Plan Parcial aprobado definitivamente) de 40 millones de $\mathrm{m}^{2}$ y un remanente, en esta misma clase de suelos de otros 50 millones. Por su parte el suelo para desarrollar (Urbanizable sin Plan Parcial aprobado) alimentaba las expectativas de crecimiento de 134 millones más de $\mathrm{m}^{2}$ (Aguiló y Verger, 1982: 32, 34-35). El crecimiento de los 80 se deslizó sobre estos planes sin las asperezas que había encontrado el de los 60 , debido a la entonces menguada presencia de planes municipales aprobados.

Como apuntábamos en otra ocasión «...el planeamiento va a remolque de la estructura territorial existente. El planeamiento no tiene esquema propio, no cuenta con la fuerza necesaria como para dibujar una nueva estructura. Se ultradimensiona todo pero con los mismos patrones locacionales. No hay Ordenación del Territorio». (Rullan Salamanca, 1989a: 630).

La clasificación del suelo establecida por el planeamiento de los 80 supone unos techos poblacionales potenciales que en el menor de los casos equivaldría a multiplicar por tres la población de las islas, tal y como puede observarse en el Cuadro III.

13 En cualquier caso hay que comentar la etapa preautonómica (1978-83) en la que se llevan a cabo importantes estudios de reconocimiento urbanístico y turístico y en la que aflorarán ya los grandes conflictos urbanísticos y territoriales de lo que será posteriormente la CAIB.

14 Según declaraciones del entonces consejero responsable del ente preautonómico (Picornell Bauzà, 1985:19-20). 
CUADro III

POBLACIÓN POTENCIAL SEGÚN PLANEAMIENTO MUNICIPAL EN 1981

\begin{tabular}{crcr}
\hline & $\begin{array}{c}\text { Suelo } \\
\text { ordenado }\end{array}$ & $\begin{array}{c}\text { Suelo para } \\
\text { desarrollar }\end{array}$ & Total \\
\hline Mallorca & 2.270 .087 & 921.307 & 3.191 .394 \\
Menorca & 228.325 & 268.841 & 497.166 \\
Pitiusas & 151.584 & 255.969 & 407.553 \\
\cline { 2 - 4 } ToTAL & 2.649 .996 & 1.446 .117 & 4.096 .113 \\
\hline
\end{tabular}

Fuente: Elaboración propia a partir de (Aguiló et al. 1982:32-35).

El territorio ordenado afectado era de unos $160 \mathrm{~km}^{2}$ de los que 60 correspondían a núcleos tradicionales y los 100 restantes a urbanizaciones turísticas que, sin embargo, sólo estaban consolidadas en un 40\% (Aguiló y Verger, 1982: 32). Ahí está la clave de otra de las características fundamentales del urbanismo del último cuarto de siglo: la extensificación genera unos niveles de consumo territorial muy superior a los del crecimiento concentrado e intensivo.

Ante tal escenario se imponía claramente la necesidad de algún tipo de regulación supramunicipal que, por encima de las miopes perspectivas locales, impusiera unos mínimos de racionalidad. En aquella época el plan supramunicipal previsto por la legislación urbanística para estas cuestiones era el Plan Director Territorial de Coordinación (PDTC). Al respecto son clarificadoras las afirmaciones que, en 1982, hacía el consejero de Ordenación del Territorio del ente preautonómico: Estos planes (los PDTCs) se diferencian de los provinciales por contar con una definición del modelo económico que regirá durante el período de vigencia del plan director. Esta discusión del modelo económico es lo que ha llevado al fracaso la tramitación de estos planes, ya que evidentemente no hay acuerdo. Traducción personal a partir de (Picornell Bauzà, 1985: 21).

Descartada pues la redacción de un PDTC se emprendió la tarea de modificar el Plan Provincial del que se llegó a presentar el avance (CGI, 1982). Con esta modificación se pretendía simplemente reajustar algunos artículos del PPOB, sin ningún cambio substancial sobre el dimensionado básico del planeamiento municipal. Descartada incluso esta vía

$$
-415-
$$


finalmente se optó, en 1983, por la suspensión de planeamiento en nueve áreas naturales y la posterior aprobación (22 de agosto de 1983) de las correspondientes Normas Subsidiarias y Complementarias ${ }^{15}$.

En los 80 los ayuntamientos democráticos reelaboraron sus planes en gran parte gracias al impulso del ente preautonómico. Una labor que fue más de adaptación a la nueva ley del suelo que de revisión real de los horizontes de crecimiento (Rullan Salamanca, 1989b). Prueba de ello es que, en 1992, once años después del recuento de 1981, los techos globales de población potencial apenas habían disminuido como puede constatarse comparando los Cuadros III y IV.

CUADRO IV

POBLACIÓN POTENCIAL SEGÚN PLANEAMIENTO MUNICIPAL EN 1992

\begin{tabular}{cc}
\hline & Población potencial total \\
\hline Mallorca & 2.931 .255 \\
Menorca & 612.674 \\
Pitiusas & 330.400 \\
TotaL & 3.874 .329
\end{tabular}

Fuente: Consejería de Obras Públicas y Ordenación del Territorio.

\section{La política de la $C A I B$}

Las actuaciones más relevantes desde el punto de vista territorial, desde la entrada en escena del Parlamento Balear, fueron las derivadas de la política sectorial turística y de las actuaciones encaminadas a la protección de los espacios naturales ${ }^{16}$.

${ }^{15}$ Ello se acometía vía artículo 51.1 del Texto Refundido de la Ley sobre Régimen del Suelo y Ordenación Urbana de 1976 (BOE de 16 y 17 de junio de 1976).

${ }_{16}$ Existen dos recopilaciones (Blasco, 1996; Blasco y Segura, 1994) de legislación turística y urbanístico-territorial publicada en el Boletín Oficial de la Comunidad Autónoma de las Islas Baleares (desde ahora BOCAIB) que abarca respectivamente hasta 1994 y 1996 y que pueden ser consultados para una mayor comodidad. En especial para la evolución de la legislación turística puede verse asimismo (Socías Camacho, 1998).

$$
-416-
$$


Ordenación Turística.-La política autonómica de ordenación turística se inaugura con la segunda ley que aprueba el Parlamento Balear desde su instauración, la Ley 2/1984, de 12 de abril, sobre alojamientos extrahoteleros. La ley contaba con un precedente claro en el anteriormente comentado decreto de infraestructuras estatal de 1970. Con esta disposición se pretende incorporar a la oferta turística legal todo el mercado real extrahotelero, principalmente apartamental que, como vimos, floreció sobremanera a partir de la crisis de 1973. Se establecen una serie de requisitos mínimos que amplían algo los del decreto de 1970, se prohíbe comercializar sin la correspondiente autorización oficial y se sigue amenazando con la declaración de Zona de Infraestructura Insuficiente a quienes no cumplan los requisitos correspondientes. Sin dejar desaparecer del todo la oferta ilegal de apartamentos, a partir de 1984 las estadísticas oficiales de oferta de apartamentos irán siendo, de año en año, más fiables.

Pero las actuaciones de ordenación turística más importantes de los 80 fueron los llamados decretos Cladera (I y II) ${ }^{17}$, en honor al consejero que los promovió, que culminaran con la Ley $7 / 1988$, de 1 de abril, de medidas transitorias de ordenación de establecimientos hoteleros y de alojamiento turístico (BOCAIB de 25 de julio de 1988). Estas disposiciones afectarán a la oferta que pretenda implantarse de nueva planta. El primitivo decreto de 1984 incorpora la exigencia al nuevo establecimiento turístico de contar, como mínimo, con $30 \mathrm{~m}^{2}$ de solar por plaza. Ello suponía un listón de densidad neta, sobre parcela, equivalente a 333 plazas/Ha.

La experiencia de aplicación del mismo constató la ineficacia de la medida toda vez que el planeamiento urbanístico mantenía el sobredimensionado antes comentado y en consecuencia la ratio de $30 \mathrm{~m}^{2} /$ plaza no frenaba en manera alguna el crecimiento (ver Fig. 2). De ahí que a los tres años, en 1987, se acomete la modificación del decreto doblando la cantidad de metros cuadrados exigidos por plaza turística nueva (60), lo que supondrá un nuevo listón de densidad neta que ahora se baja a 167 p./ha. El anuncio de este decreto produjo una avalancha de solicitudes especulativas —el llamado «efecto Cladera II»- perfectamente reflejado en la Figura 2.

17 Se trata de los Decretos 30/1984 de Medidas de ordenación de establecimientos hoteleros y alojamientos turísticos y el 103/1987 de Medidas transitorias de ordenación de establecimientos hoteleros y alojamientos turísticos. 


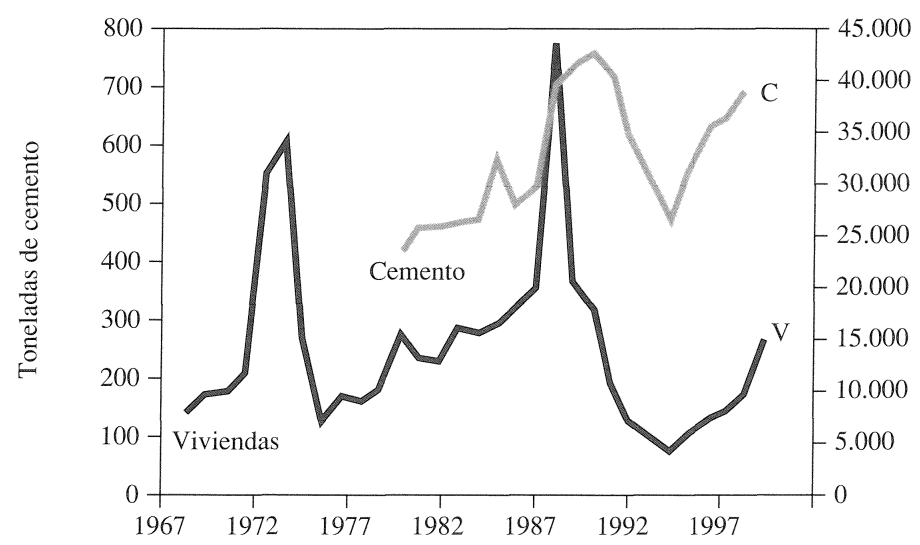

FIG. 2.-Evolución del consumo de cemento y del visado de viviendas en las Islas Baleares.

El decreto Cladera II y su posterior reconversión en la Ley 7/1988 venía apadrinado por el llamado Libro Blanco del Turismo en Baleares (LBTB, 1987), promovido desde la Consejería de Turismo y elaborado por la Universidad de las Islas Baleares. En concreto, entre las 41 páginas de conclusiones, se aconseja la sumisión de la planificación municipal a la turística - apoyando la intervención urbanística que realizará el POOT a partir de 1995- y la necesidad de profundizar más, cuantitativa y cualitativamente, en la dirección apuntada por el Decreto 30/1984 de 10 de mayo de la Consejería de Turismo. (LBTB, 1987: II, 373). Dicho sea de paso que tal propuesta está inexplicablemente encallada entre las recomendaciones referentes a la protección medioambiental.

La ley Cladera es planteada como norma transitoria hasta la aprobación del futuro Plan Director Sectorial de Ordenación de la Oferta Turística ${ }^{18}$. A estas alturas ya resultaba más que evidente que, sin regula-

18 Se trata de una de las figuras diseñadas por la Ley de Ordenación del Territorio de 1987. Los planes referidos a ámbitos turísticos - los POOTs - se aprobarán, para Mallorca, en 1995 y, para Ibiza y Formentera, en 1997. Con lo cual la Ley 3/1987 ha seguido vigente para la isla de Menorca. 
ción urbanística, se hacía muy difícil controlar el crecimiento de la oferta. Además la disposición de 1987 establece que el suelo afectado por nuevas plazas (además de la ratio de $60 \mathrm{~m}^{2} / \mathrm{p}$., excepto en cascos urbanos tradicionales y edificios catalogados) deberá ser destinado a uso exclusivamente turístico ${ }^{19}$, los nuevos hoteles deberán ser de 4 ó 5 estrellas y se incentiva la reconversión de la planta obsoleta, en cuyo caso sí será posible la obertura de hoteles de 3 estrellas, nunca de 1 ó 2.

La reconversión de la oferta obsoleta (más de diez años) constituye la gran novedad de la Ley inaugurando una línea de actuación destinada a ser la estrella de las políticas turísticas de los 90. La incentivación a la reconversión se plantea en base a autorizar nuevos hoteles, que ahora sí pueden ser de 3 estrellas, con ratios de densidad inferior a los $60 \mathrm{~m}^{2} /$ plaza. En cualquier caso las reconversiones deben llevarse a cabo sin cambiar de zona turística y los solares liberados se prevé sean destinados al esponjamiento de la zona turística en cuestión.

La aprobación de estas regulaciones generó alguna que otra descoordinación entre las administraciones turística y urbanística, las exigencias de turismo no tenían porqué estar contempladas en los planes municipales, con lo que podían darse casos de edificios legalizados urbanísticamente e ilegalizables turísticamente. Para resolver el tema se aprueba, en 1989, el decreto que regula los trámites necesarios y su encadenamiento para abrir un nuevo alojamiento turístico ${ }^{20}$. Se trata de las llamadas autorizaciones previas de la administración turística, imprescindibles para la obtención de la licencia municipal y, consecuentemente, para la ulterior autorización turística de abertura.

En cualquier caso todas estas medidas afectarían a la nueva oferta turística, no a la existente, a ésta se dedicarán los llamados planes de modernización ${ }^{21}$. Afectarán especialmente a la planta anterior a 5 de junio de 1984 (Cladera I) que deberán superar una inspección especial para conseguir la calificación de hotel o apartamento modernizado. La no superación de la inspección puede comportar el cierre del establecimiento.

19 Ahí aparece por primera vez la idea de separación de los usos turísticos y residenciales que posteriormente se generalizará a partir de otras disposiciones.

20 Decreto 60/1989, de 22 de mayo, que regula el procedimiento de expedición de autorización previa y de apertura de construcciones, obras e instalaciones de empresas $y$ actividades turísticas (BOCAIB de 8 de junio de 1989).

${ }^{21}$ Regulados por la Ley 3/1990, de 30 de mayo, por la cual se crea y regula el plan de modernización de alojamientos turísticos existentes en Baleares (BOCAIB de 19 de junio de 1990). 
Todas estas medidas que venimos comentando afectan, sectorialmente, al establecimiento turístico por dentro o, en todo caso, a su relación con la superficie de la parcela sobre la que se asienta, todavía arquitectura más que urbanismo. Nada que ver aún con medidas directamente urbanísticas y, mucho menos, territoriales.

Protección urbanística de Espacios Naturales.-Paralelamente al proceso de regulación de la actividad turística se está asistiendo, en la década de los 80, a un importante debate territorial para la protección de las áreas naturales del archipiélago que se veían amenazadas por la ola de crecimiento general de la década. Ambas políticas suponen medidas proteccionistas ante la avalancha de crecimiento general del momento, las primeras pretenden proteger la oferta turística, las segundas pretenden proteger los espacios naturales. El resto, lo no turístico ni natural, quedará a la libre aleatoriedad del capricho municipal en su planeamiento.

Así, si la segunda ley autonómica fue la turística 2/1984, la primera es la llamada ley de ANEIs ${ }^{22}$ que legitima al Parlamento para la reclasificación puntual de sectores urbanizables según los planes municipales, que se consideren de especial interés. Se trata de una ley marco que deberá aplicarse posteriormente a los casos específicos que el Parlamento considere. La declaración de ANEI, que entre 1984 y 1990 se llevó a cabo sobre 12 espacios naturales (Blasco, 1996: 78), suponía la clasificación del suelo afectado como Suelo no Urbanizable de especial protección que en el futuro se debía regir por un plan especial que se redactase ad hoc.

Siete años después, la Ley de Espacios Naturales de $1991^{23}$, afectando 1/3 del archipiélago ${ }^{24}$, cierra el goteo de declaraciones de ANEI, reclasifica algunos sectores urbanizables y establece niveles de protección urbanística en Suelo No Urbanizable que van desde la inedificabilidad hasta las 3 Hectáreas de parcela mínima ${ }^{25}$.

${ }^{22}$ Ley 1/1984, de 14 de marzo, de ordenación y protección de áreas naturales de interés especial (BOCAIB de 9 de mayo de 1984).

${ }^{23}$ Ley 1/1991, de 30 de enero, de espacios naturales y de régimen urbanístico de las áreas de especial protección de las Islas Baleares (BOCAIB de 9 de marzo).

${ }^{24}$ La delimitación se basa en el llamado «Inventario Abierto de Espacios Naturales de Protección Especial, Baleares. Revisión 1984» del ICONA, así como en documento «Áreas a proteger en Baleares» elaborado por el INESE para el Gobierno Balear.

${ }^{25}$ La LEN, sin embargo, sería modificada radicalmente para las islas de Ibiza y Formentera al año siguiente (Ley r/1992) hasta su exclusión, de hecho, de las principales medidas protectoras de la misma. Para las características principales de la LEN y su modificación de 1992 puede consultarse (Rullan Salamanca, 1995a:161-62 y 177). 
Lo sustancial de la LEN, contrariamente al papel que se le ha atribuido en la década de los 90, fue la reclasificación de los suelos urbanizables de los planes municipales - los no incluidos en el famoso anexo II-. Efectivamente, la LEN intenta frenar la expansión del segundo boom turístico, el crecimiento extensivo, sobre las áreas naturales, no la dispersión de edificación sobre el suelo no urbanizable. La LEN reclasificó e imposibilitó la nueva clasificación, no frenó la edificación.

Precisamente durante los 80 empezó a hacerse notar una de las principales características de los 90, la dispersión de edificaciones en suelo rústico (Rullan, Manchado y Marcús, 1998). A tal efecto, en 1988 y 1989, el Gobierno Balear utilizó nuevamente la fórmula, estrenada en 1983, de suspensión de planeamiento y sustitución por Normas Subsidiarias para levantar el listón de la edificabilidad en no urbanizable. Al mismo tiempo que estrenaba (1988) la figura de parque natural para uno de los espacios más emblemáticos de conservacionismo mallorquín: la Albufera de sa Pobla-Muro ${ }^{26}$. Será precisamente otra medida reguladora de afección al SNU la que se aprueba en 1988, la Ley 12/1988, de Campos de Golf (BOCAIB de 3 de diciembre de 1988). Dicha ley faculta a las comisiones de urbanismo a la declaración de interés social de los campos de golf con una oferta complementaria, para rentabilizar la operación, consistente en un hotel o aparthotel de 450 plazas ${ }^{27}$.

Mención aparte merece la aprobación, en 1987, de la Ley 8/1987, de 1 de abril, de Ordenación Territorial de las Islas Baleares (BOCAIB de 23 de abril de 1987), la LOT. Se trata de una nueva ley marco en conexión con cuantas otras se han ido promulgando a lo largo de los 80 en otras comunidades autónomas (Cruz Mera, 1997: 584-89; Rullan Salamanca, 1995b: 180-3). Como en otras comunidades autónomas la LOT balear es, casi exclusivamente, una ley de figuras de planificación supramunicipal que establece una nueva jerarquía de dudosa necesidad objetiva (Rullan Salamanca, 1995a: 192-93). A pesar de todo se trata de la norma que mar-

${ }^{26}$ La adicional tercera de la LEN marca el mapa mínimo de Espacios Naturales Protegidos que deben ser declarados conforme a lo dispuesto en la Ley 4/1989, de Conservación de los Espacios Naturales y de la Flora y Fauna Silvestre. Se trata de siete áreas que deberán añadirse a la de la Albufera y de las que, a finales de los 90, se han declarado cinco.

27 El campo debe se de, como mínimo, 18 hoyos y 60 hectáreas, no pueda ubicarse en espacios naturales protegidos por prescripción de la posterior Ley 1/1991 (la LEN) y debe regarse preferentemente con agua depurada. La aplicación de la Ley de Campos de Golf posibilitará una oferta que, a finales de los 90 , ronda la quincena de instalaciones.

$$
-421-
$$


cará el camino a seguir instrumentalmente para la ordenación del territorio.

En resumen, la política territorial balear, ante la ola de crecimiento de los 80, reaccionó únicamente ante dos trincheras, la turística y la de protección de los espacios naturales. Aumentó la ratio turística para nuevos alojamientos hasta los $60 \mathrm{~m}^{2}$ de parcela por plaza, reclasificó algunos suelos urbanizables y trazó una malla protectora de la nueva urbanización sobre lo espacios naturales que - cuando la demanda ya no se dirigía únicamente hacia la urbanización nueva planta—se demostrará completamente insuficiente. Efectivamente, la dispersión de edificación del tercer boom turístico — década de los 90- se demostrará plenamente compatible con los listones que la LEN establece a las edificaciones.

\section{Crecimiento y dispersión en los años 90}

La curva expansiva de los 90 tiene, como la de los 80 , sus efectos en la reconfiguración de una oferta cada vez mayor y más diversificada. La explosión de diversidad será posible gracias a lo lejano que se establece el listón del dimensionado en los planes municipales. En efecto, éstos siguen manteniendo el listón en torno a los 4 millones de población potencial en 1998, frente al 1,5 millones que puede albergar al parque inmobiliario construido. Dicho parque se distribuye aproximadamente al $50 \%$ entre usuarios permanentes - población de derecho- y ocasionales - turismo y segunda residencia ${ }^{28}$.

En cualquier caso el fenómeno más característico, aunque no el único, del tercer boom turístico será el de la compra por parte de extranjeros de propiedades inmobiliarias tanto rústicas como urbanas (Seguí Ramon, 1998). Podríamos decir que éste es el fósil guía de la tercera gran pulsación de crecimiento. El fenómeno lleva una velocidad galopante desde el momento en que la integración europea se va haciendo más efectiva ${ }^{29}$.

${ }^{28}$ Datos aportados por el Gobierno Balear en la presentación del proyecto de Ley de Directrices de Ordenación Territorial (1999).

${ }^{29}$ Durante los años 1996 y 1997 se realizaron en las Islas Baleares 4.831 y 5.167 transmisiones de bienes inmuebles a favor de no residentes, según datos aportados por la Consejería de Economía y Hacienda del Gobierno Balear. Estas cifras suponen un 13\% del total de transmisiones realizadas en dichos años.

$$
-422-
$$


El proceso de residencialización afecta también al suelo rústico en magnitudes hasta ahora desconocidas inundando, en una dispersión incontrolada, los antaño agrarios campos insulares (Rullan et al., 1998). Las Islas Baleares - especialmente Mallorca y las Pitiusas- son, a final de milenio, la nueva frontera para el nuevo colonizador europeo. La compra y apropiación privada de los paisajes insulares es la nota dominante ante un planeamiento que, con un boom turístico de retraso, empieza ahora tímidamente a reclasificar suelos urbanizables cuando la demanda ya se ha desviado hacia el rústico y el urbano, con cierto valor añadido, como el casco antiguo de Palma y los pueblos de interior. Aquel espacio urbano al que la población autóctona había dado la espalda a partir del primer boom turístico ahora será revalorizado y europeizado.

Leyes y planes turísticos.-Los 90 presentarán importantes novedades en lo referente a leyes y planes para intentar regular, encauzar, parar o promover, según los casos, la nueva ola de expansión territorial. Varios serán los frentes de actuación; ordenación del territorio, política turística, suelo rústico y urbanismo. Cuatro frentes que se enlazan y entremezclan competencialmente hasta el punto que difícilmente podemos deslindar un tipo de actuación de otro. Contrariamente a lo que ocurrió en los 80, con las dos políticas claramente definidas de protección de los espacios naturales y de los turísticos, en los 90, todas las políticas que se implementan son directamente interactuantes, la densidad del sistema urbano lo interrelacionada todo: población, poblamientos, leyes y planes.

Con este escenario podríamos analizar cualquiera de los frentes de actuación. Sin embargo parece más coherente empezar por los planes que se derivan de la Ley de Ordenación Territorial de 1987 (LOT), ley marco aprobada, recordémoslo, en 1987, en el momento cumbre del segundo boom turístico. La nueva jerarquía de planificación supramunicipal que marca la LOT estará encabezada por las Directrices de Ordenación Territorial (DOT) que, a escala de comunidad autónoma, debe establecer el esquema general de ordenación del territorio, el modelo de organización territorial. Al mismo tiempo las DOT fijarán los planes supramunicipales necesarios para desplegar la política territorial, unos planes que podrán ser de tipo sectorial/vertical - como los Planes Directores Sectoriales de Coordinación (PDTC) o los Planes de Ordenación del Medio Natural (POMN) — o integral/horizontal — como los Planes Te- 
rritoriales Parciales (PTP)-. Los primeros afectarán sectores concretos los segundos harán lo propio con ámbitos geográficos específicos.

Si bien la metodología marcada por la LOT señala a las DOT como primer plan a elaborar y aprobar, se posibilita la aprobación anticipada de PDS, PTP o POMN si, caso a caso, el Parlamento va aprobando los correspondientes criterios que, según la secuencia establecida por la LOT, deberían establecer las DOT. Por esta vía se han ido aprobando, a lo largo de los años 90, nueve diferentes PDS que afectan a seis sectores: Residuos Sólidos Urbanos, Puertos Deportivos, Oferta Turística, Comercio, Canteras y Carreteras. Se trata, como se ve, de temas que el segundo boom turístico de los 80 había disparado por encima de los límites controlables. La política territorial se empieza implementando la forma claramente sectorial pues ningún PTP ni POMN, si bien se han empezado los trabajos de algunos, ha llegado a la aprobación definitiva.

La ordenación supramunicipal de los aspectos derivados de la recogida, tratamiento y eliminación de residuos sólidos urbanos inaugurará, entre 1990 y $1994^{30}$, la familia de planes sectoriales insulares irrumpiendo así en la forma de hacer ordenación territorial prevista por la LOT. Los citados planes, desde el punto de vista del funcionamiento territorial, tendrán poca relevancia. De hecho lo que hacen es organizar la recogida de residuos - cuya producción se había disparado desde el segundo boom turístico- creando las llamadas estaciones de trasferencia que, distribuidas en función de los núcleos urbanos, compactan los residuos antes de su traslado a las estaciones de incineración (Mallorca), compost (Menorca) o vertedero controlado (Ibiza).

Otro fenómeno que asimismo se desborda gracias al crecimiento de los 80 es el referido a las instalaciones náuticas de ocio. Así, en 1994 verá la luz el PTP de puertos deportivos ${ }^{31}$, este plan sería anulado

${ }^{30}$ En primer PDS se aprueba mediante el Decreto 8\%/1990 de 20 de septiembre, de aprobación del Plan Director para la gestión de los residuos sólidos urbanos de la isla de Mallorca (BOCAIB de 13 de octubre de 1990). Un plan que ya ha sufrido dos modificaciones (1993 y 1999). Menorca, por su parte, ve aprobado su plan mediante el Decreto 76/199, de 24 de julio, de aprobación del Plan Director de Residuos Sólidos de la isla de Menorca (BOCAIB de 15 de agosto de 1991). Modificado asimismo en 1993. El Decreto 68/1994, de 13 de mayo, de aprobación del Plan Director para la gestión de los Residuos Sólidos Urbanos de la isla de Ibiza (BOCAIB de 7 de junio de 1994) completará el mapa ordenando el tema en la mayor de las Pitiusas.

${ }_{31}$ Decreto 61/1994, de 13 de mayo, por el cual se aprueba el Plan Director de Puertos Deportivos e Instalaciones Náuticas de las Islas Baleares (BOCAIB de 2 y 4 de julio de 1994).

$$
-424-
$$


posteriormente por los tribunales por invasión de competencias del estado reguladas por la ley de costas de 1988. El plan pretendía clasificar la costa balear en función del tipo de instalaciones que pudieran construirse con un dimensionado global cercano a los 15.000 amarres.

El notable aumento del poder adquisitivo de la demanda balear provocará asimismo una reconversión radical de su oferta comercial, a esta circunstancia pretende responder el PDS de equipamientos comerciales (1996) ${ }^{32}$. El plan persigue el control de una actividad que, como la comercial, se ha desbordado con respeto a la dinámica que venía siguiendo. El plan crea un registro de establecimientos comerciales, regula específicamente las grandes superficies (de las que declara una moratoria hasta el año 2002) obliga al planeamiento urbanístico a separar el comercial de otros usos (en línea con la doctrina turística) que, exceptuando las grandes superficies, no podrá superar una densidad municipal superior a $3,5 \mathrm{~m}^{2}$ calificados por población equivalente ${ }^{33}$.

Dos sectores enormemente influidos por los crecimientos de los 80 y 90 fueron las canteras - por haberse disparado el sector de la construcción-y el de carreteras - al aumentar notoriamente el parque automovilístico de la comunidad - ambos polémicamente enfrentados al paisaje balear. Sobre estas materias se aprobarán los correspondientes PDS de Canteras ${ }^{34}$ y Carreteras ${ }^{35}$. La política de carreteras, desde 1983, se había venido implementando a base de proyectos concretos sin el necesario plan de referencia, hecho que habían advertido algunas sentencias judiciales, hasta que, quince años después se aprueba un plan que venía a reconocer la red que, proyecto a proyecto, se había venido construyendo sin plan explicitado.

${ }^{32}$ Decreto 217/1996, de 12 de diciembre, por el que se aprueba el Plan Director Sectorial de Equipamientos Comerciales de las Islas Baleares (BOCAIB de 21 de enero de 1997).

${ }_{33}$ La población equivalente se obtiene sumando población de derecho, plazas de segunda residencia y $1 / 4$ de las plazas turísticas del término municipal.

${ }^{34}$ Decreto 7\%/1997, de 11 de junio, por el que se aprueba definitivamente el Plan Director Sectorial de Canteras de las Islas Baleares (BOCAIB de 1 de julio de 1997).

${ }_{35}$ Decreto 87/1998, de 16 de octubre, por el cual se aprueba definitivamente el Plan Director Sectorial de Carreteras (BOCAIB de 22 de octubre de 1998). 
En este repaso a los PDS hemos omitido deliberadamente los dos que, desde 1995 y 1997 respectivamente, regulan urbanísticamente la oferta turística de Mallorca ${ }^{36}$ e Ibiza-Formentera ${ }^{37}$, los llamados POOT ${ }^{38}$. Sus antecedentes están claramente anclados en la normativa turística de los 80, especialmente la Ley $7 / 1988$, al tiempo que representan el definitivo salto de la ordenación y política turística al campo urbanístico. Efectivamente, los POOT, aunque son PDS que emanan de la legislación territorial (LOT), implican determinaciones en realidad estrictamente urbanísticas. Los POOT no replantean la ordenación territorial del sector sino que se limitan a establecer parámetros, densidades, estándares y sistemas urbanísticos de reconversión de las zonas turísticas existentes.

La clave, en palabras del consejero que impulsó inicialmente los POOT, está en controlar la densidad para evitar situaciones de saturación que superen la capacidad de carga de las zonas (Cladera Cladera, 1993:66-67). Para justificar tal objetivo se invoca la teoría y práctica urbanística de Walter Gropius, planificador urbano alemán de los años $20^{39}$.

Los POOT actúan casi exclusivamente sobre las llamadas zonas turísticas - 37 en Mallorca, 11 en Ibiza y 3 en Formentera-delimitadas a partir de las líneas exteriores de los suelos urbanos y urbanizables según los planes municipales vigentes en el momento de su aprobación definitiva. Estas zonas se protegen de futuras expansiones mediante las llamadas Zonas Limítrofes de Protección Costera (ZLPC) y Posterior (APP) que las contornearán (Fig. 3).

En el interior de las zonas turísticas, ante futuras revisiones, se impide superar la densidad vigente según el plan municipal en los suelos ordenados (urbano y urbanizable con plan parcial aprobado), mientras que para los no ordenados (urbanizable sin plan parcial aprobado) la den-

${ }^{36}$ Decreto 54/1995, de 6 de abril, por el que se aprueba el Plan de Ordenación de la Oferta Turística de la isla de Mallorca (BOCAIB de 30 de mayo y 22 de junio de 1995).

${ }^{37}$ Decreto 42/1997, de 14 de mayo, por el que se aprueba el Plan de Ordenación de la Oferta Turística de las islas de Ibiza y Formentera (BOCAIB de 12 de junio de 1997).

${ }^{38}$ En Menorca se ha abandonado la línea sectorial turística para optar por la integral. Se ha descartado la redacción del POOT incluyéndose sus determinaciones en el futuro Plan Territorial Parcial de Menorca.

${ }^{39}$ Gropius es uno de los representantes más distinguidos del llamado funcionalismo racionalista que, entre guerras, aplicaron al urbanismo los principios de la producción industrial en serie. Para un conocimiento más extenso del autor puede consultarse (Gravagnuolo, 1998:366-77). 


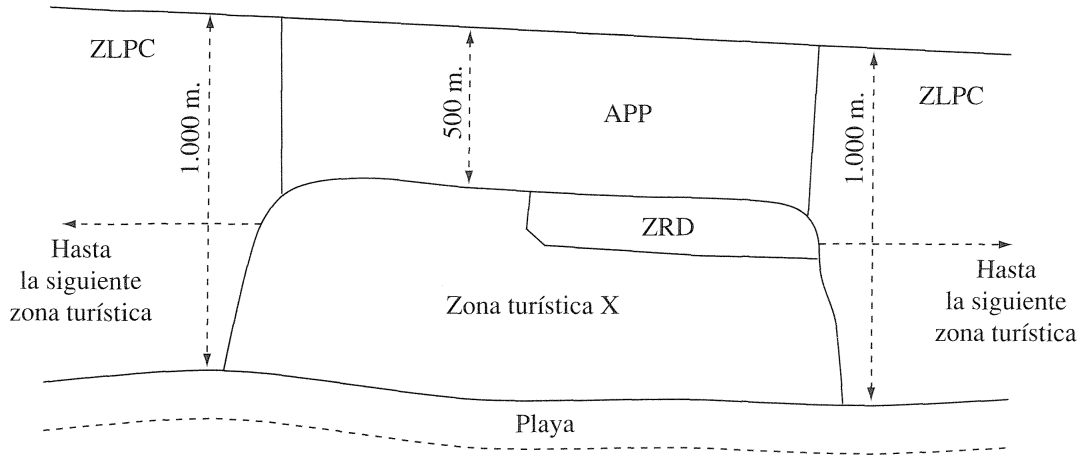

ZLPC: Zona limítrofe de protección costera

APP: Área de protección posterior

ZRD: Zona de reserva y dotacional

FIG. 3.-Los POOTs, para Mallorca e Ibiza-Formentera, delimitan las zonas turísticas a partir de las líneas de suelo urbano y urbanizable según el planeamiento municipal y cierran la posibilidad de extensión de la urbanización más allá de su perímetro.

sidad se limitará a 60 hab./Ha ${ }^{40}$. A partir de ahí el POOT generaliza los $60 \mathrm{~m}^{2}$ de solar/plaza ${ }^{41}$ que ya se había establecido en 1988 , obliga a separar usos, da parámetros edificatorios y establece estándares mínimos de algunos equipamientos por zonas.

Por último, como aspecto quizás más emblemático del POOT, se establecen los llamados mecanismos de reconversión en y entre zonas turísticas de cada una de las islas (Ramis Ramos, 1998: 23-26). Para

40 Antes de la aprobación del primer POOT (1993 y 1994) ya se había regulado la forma en que los planes municipales debían contabilizar las densidades de población potencial según el planeamiento. Los Decretos del 93 y 94 serán sustituidos posteriormente por el 2/1996, de 16 de enero, sobre regulación de las capacidades de población en los instrumentos de planeamiento general y sectorial (BOCAIB de 30 de enero de 1996). La práctica habitual de los planes, para cuantificar la población potencial, había sido la consideración de los llamados índices zonales de densidad. La capacidad demográfica real que suponía la aplicación directa de las ordenanzas de edificación era muy superior a la derivada, con carácter global, de aquellos índices. Para evitar tal circunstancia el decreto obliga a los planes municipales a establecer los llamados índices de intensidad de uso - turístico y/o residencial- que al ser de aplicación tanto global como a nivel de ordenanza pretende aproximar los estudios de potenciales urbanísticos como la expectativa real que establece el planeamiento.

${ }_{41}$ De hecho, en Mallorca, los aumenta a 70 en 11 zonas y a 75 en otras 4 . 
que ello sea urbanísticamente posible, en los casos más conflictivos, se obliga, si hace falta, a la elaboración de los correspondientes Planes Especiales. Se trata de los llamados mecanismos de intercambio de aprovechamiento (art. 20) que, pudiendo cambiar la zona turística, se promueve el intercambio de solares entre propietarios y el organismo gestor del plan para conseguir espacios libres públicos (ELP) y equipamientos para las diferentes zonas turísticas. Por su parte, la regulación y fomento de la reconversión se establece en el seno de cada zona (art. 21), regula mecanismos de reconversión incentivados a partir de la rebaja de la ratio turística correspondiente aunque, en este caso, no es estrictamente necesario el paso del viejo solar a ELP.

Para conseguir el suelo necesario que permita materializar los objetivos del plan, el POOT ordena a los planes municipales la delimitación de las llamadas Zonas de Reserva y Dotacional (figura 3) que, reclasificando suelo rústico si hace falta, ofrezcan la posibilidad de materializar los nuevo estándares de equipamiento y proporcionen solares para la reconversión, únicas finalidades a las que pueden ser destinadas la ZRD.

El POOT, cinco años después de su aprobación en Mallorca, no ha conseguido regular plenamente la dinámica urbanística del sector, prueba de ello es que la oferta ha seguido aumentando desviándose hacia modalidades que ahora se sitúa en el parque de viviendas residenciales y, por lo tanto, no controlada por la administración turística. El análisis de campo realizado para la elaboración de POOT ya revelaba, para 1990, que más del 50\% del parque residencial construido no era de uso hotelero ni apartamental (Rullan Salamanca, 1995a:170), la no aprobación de la mayoría de planes municipales que debían adaptarse al POOT ha hecho el resto.

La desviación de la oferta hacia el turismo residencial es perceptible claramente en la llegada a los aeropuertos baleares de pasajeros en la modalidad «seat only» que, en 1998, se acercaba al 10\% de todo el movimiento aeroportuario o, asimismo, en el aumento de la oferta turística no reglada (apartamentos rústicos clandestinos y viviendas residenciales en régimen de arrendamiento urbano) que, en 1997 ha sido estimada en 60.000 plazas (13\% de la oferta) y 7,2 millones de estancias $\left(7,3 \%\right.$ de la demanda) ${ }^{42}$ (Bardolet, 1999). Estas 60.000 plazas pueden al-

${ }^{42}$ El desfase entre ambos porcentajes es debido a la mayor estacionalidad de las modalidades no regladas. 
canzar las 100.000 en momentos punta de agosto pues se da un flujo de la demanda hacia el parque inmobiliario de los residentes cuando el de no residentes alcanza ciertos niveles de saturación. La frontera entre el parque inmobiliario de segunda residencia local y extranjera es una amplia banda, cada vez más extensible y de muy pequeño gradiente que permite extender la oferta más allá de lo estrictamente turístico. Las dos aguas se están juntando y, de seguir la tendencia, pronto se habrán entremezclado totalmente. Una entremezcla que, con la caída de la estacionalidad, se dará, también, en el tiempo.

En relación al fenómeno se ha señalado (Aguiló Pérez, 1998:458) el peligro de una fuerte expansión residencial que pudiera hacer quebrar las políticas turísticas restrictivas que se anuncian. Prueba de todo lo que vamos diciendo es que, como ocurriera con la Ley 2/1984, para intentar reglar la nueva tipología de oferta turística, en 1998 se aprueba el decreto que pretende controlar las viviendas vacacionales de uso turístico ${ }^{43} \mathrm{y}$, desde 1991, los alojamientos de agroturismo y turismo rural $^{44}$.

Para frenar el crecimiento de la oferta de alojamiento convencional del tercer «boom» turístico se aprueba, en 1998, la llamada moratoria turística ${ }^{45}$ hasta la entrada en vigor de la Ley General Turística ${ }^{46}$. Los decretos y leyes de los 80 se han demostrado completamente insuficientes para encauzar razonablemente el crecimiento, se imponía así una nueva política de casi números clausus. La ley de moratoria turística generaliza, para todo el archipiélago, la necesidad de dar de baja un número equivalente de plazas - calculado según la fórmula del artículo 20 del POOT en Mallorca-para conseguir la autorización previa de instalaciones de nueva planta. Regla de la que sólo se excluyen los alojamientos de excepcional interés turístico. Con esta medida se cierra el ciclo iniciado en los años 50, se cierra el primer (hoteles) y segundo

43 Se trata del Decreto 8/1998, de 23 de enero, por el que se regulan las viviendas turísticas de vacaciones en el ámbito de la CAIB (BOCAIB de 23 de enero de 1998).

${ }_{44}$ Decreto 62/1995, de 2 de julio, por el cual se regula la prestación de servicios turísticos en el medio rural de las Islas Baleares (BOCAIB de 24 de junio de 1995). Este Decreto contaba ya con antecedentes de 1991, 1992 y 1995 en paralelo, como vemos, al tercer boom turístico.

${ }^{45}$ Ley 4/1998, de 19 de mayo, de medidas transitorias relativas al otorgamiento de autorizaciones previas de construcciones. Obras e instalaciones de empresas y actividades turísticas (BOCAIB de 25 de mayo de 1998).

${ }^{46}$ En línea con la que, en 1995, se aprobó para las Islas Canarias (Ley 7/1995, de 6 de abril, del Parlamento Canario). 
(apartamentos) boom turístico. Ahora, la nueva frontera de crecimiento se ubica en el campo de las viviendas vacacionales, tanto rústicas como urbanas, tanto en propiedad como en alquiler.

Regulaciones urbanísticas.-Es precisamente el uso residencial desarrollado en suelo rústico o previsto en urbanizable el que centrará el otro gran tema de la década de los 90 en las Islas Baleares. El suelo rústico, sin más limitación para el desarrollo que el derivado de sus características objetivas, ya había experimentado un notable proceso de edificación residencial en los años 80. Las políticas de aquella época se centraban, recordémoslo, únicamente en las áreas naturales -declaraciones de ANEI y Normas Subsidiarias supramunicipales de 1983, 1988 y 1989-, mientras que en los 90 se hará necesario empezar a regular - al principio como siempre tímidamente- la edificación en los $2.662 \mathrm{~km}^{2}$ de suelo rústico común.

En este contexto se inscribirá el acuerdo del pleno del Consell Insular de Mallorca ${ }^{47}$ de establecer, mediante una nueva norma subsidiaria supramunicipal, un mínimo de parcela de $7.000 \mathrm{~m}^{2}$ para que no se de peligro de formación de núcleo de población ${ }^{48}$. Con la aprobación en 1997 de la Ley del Suelo Rústico (LSR) ${ }^{49}$, entre otros aspectos, se dobla la superficie mínima que deberán exigir los planes para posibilitar la edificación en rústico ${ }^{50}$. Con la LSR se cubren supramunicipalmente los $2.662 \mathrm{~km}^{2}$ de suelo rústico común. Con la LEN y la LSR es cuantificable el techo de crecimiento máximo posible en esta clase de suelo a partir de la normativa supramunicipal, a escala de ordenación del territorio. El Cuadro V muestra la magnitud superficial de esta nueva frontera para el crecimiento.

${ }^{47}$ La Ley 9/1990, de 27 de junio (BOCAIB de 24 de julio de 1990), atribuye las competencias de urbanismo y habitabilidad a los consejos insulares de Mallorca, Menorca e Ibiza-Formentera.

${ }_{48}$ Acuerdo del Pleno del Consejo Insular de Mallorca, de día 5 de septiembre de 1994, relativo a la aprobación de la norma subsidiaria sobre parcela minima a efectos de formación de núcleo de población en suelo no urbanizable o urbanizable no programado (BOCAIB de 22 de septiembre de 1994).

${ }_{49}$ Ley 6/197\%, de 8 de julio, del Suelo Rústico de las Islas Baleares (BOCAIB de 15 de julio de 1997).

${ }^{50}$ No obstante deja $7.000 \mathrm{~m}^{2}$ para Ibiza así como en las parcelas anteriores a 1956 en Mallorca y Menorca y en 6.000 para Formentera. Tales mínimos sólo podrán ser aumentados por los planes territoriales o municipales, con ello se aborta la posibilidad de una nueva norma subsidiaria supramunicipal que precisamente estaba planteando el Consell Insular de Mallorca y que establecía muchas más restricciones a la edificación en no urbanizable. 
CuAdro V

EL SUELO RÚSTICO EN LAS ISLAS BALEARES $\left(\mathrm{km}^{2}\right)$

\begin{tabular}{|c|c|c|c|c|}
\hline \multirow[b]{2}{*}{ Islas habitadas } & \multirow{2}{*}{$\begin{array}{l}\text { Suelo urbano } \\
\text { y urbanizable }\end{array}$} & \multicolumn{2}{|c|}{ Suelo rústico } & \multirow[b]{2}{*}{ Total $\mathrm{km}^{2}$} \\
\hline & & $\begin{array}{l}\text { Protegido } \\
\text { (LEN'91) }\end{array}$ & $\begin{array}{l}\text { Común } \\
\text { (LSR'97) }\end{array}$ & \\
\hline Mallorca & 252 & 1.386 & 2.002 & 3.640 \\
\hline Menorca & 45 & 294 & 363 & 702 \\
\hline Ibiza-Formentera & 46 & 280 & 197 & 623 \\
\hline TOTAL & 343 & 1.960 & 2.662 & 4.965 \\
\hline
\end{tabular}

Fuente: Elaboración propia a partir de estadísticas oficiales y (DOT-Diagnòstic, 1997).

Las posibilidades residenciales que ofrece este suelo alcanzaría, haciendo cálculos a la baja, los 580.000 habitantes ${ }^{51}$. Esta cifra nos muestra cómo estamos nuevamente ante un escenario sin límites reales ante la nueva modalidad de expansión residencial. Como ocurrieras en los 60-70 y en los 80, a los planes del tercer boom turístico - que, recordémoslo, mantienen un dimensionado potencial en urbano y urbanizable de 4 millones de habitantes - también se les escapa todo tipo de control efectivo sobre la modalidad de oferta más emergente: el parque residencial no reglado por la normativa turística. Los 4 millones de potencialidad en suelo urbano y urbanizable superan los 4,5 si agregamos el potencial del suelo rústico. Comparando esta cifra con los 1,5 millones de habitantes que posibilita el parque construido ${ }^{52}$ se entiende que se esta afrontando el tercer boom turístico como se hizo con el primero y el segundo: sin ningún tipo de planificación efectiva, con un listón al crecimiento que, por lejano, resulta inoperante.

El sobredimensionado de los planes municipales se debe, sobre todo, a las posibilidades edificatorias que permite el suelo ordenado. En

51 Para su cálculo hemos considerado que: 1) un 10\% del suelo rústico está ocupado por instalaciones urbanas o incompatibles de hecho con la vivienda; 2) en zonas LEN se ha dividido el correspondiente $90 \%$ por $20 \mathrm{Ha}$, considerando que las ANEIs inedificables compensan con las ARIPs (3 Ha); 3) No se han considerado los casos de edificabilidad en $0,7 \mathrm{Ha}$ de Mallorca y Menorca y 4) se ha considerado un coeficiente medio de 3 habitantes por vivienda. El resultado (580.000) es superior al techo establecido por el planeamiento municipal que, en 1996, ascendía a 507.765 (Rullan et al., 1998: 139).

52 Según estimaciones oficiales recientes (1998) si bien anteriormente se había dado la cifra de 1,6 (DOT-Diagnòstic, 1997: 191-94).

$$
-431-
$$


efecto, el suelo ordenado (urbano y urbanizable con plan parcial aprobado) ha experimentado, en catorce años, una expansión superior al 50\%, a un ritmo anual del 3,1\% entre 1981 y 1995 (Cuadro VI).

CUADRO VI

EVOLUCIÓN DEL SUELO URBANO Y URBANIZABLE $\left(\mathrm{km}^{2}\right)$ EN LAS ISLAS BALEARES

\begin{tabular}{cccc}
\hline Año & Ordenado & No ordenado & Total \\
\hline 1981 & 161 & 224 & 385 \\
1995 & 247 & 96 & 343 \\
\hline
\end{tabular}

Fuente: Elaboración a partir de (Aguiló, 1982 \#364: 34; DOT-Diagnòstic, 1995 \#378: 195).

Más de $86 \mathrm{~km}^{2}$ han engrosado los espacios disponibles para la promoción inmobiliaria a un ritmo de $6 \mathrm{~km}^{2}$ de media anual, un perímetro expansivo de colonización urbana que, al ritmo de 614 Hectáreas anuales, ha ido cubriendo los abandonados suelos rústicos ante la competencia de la nueva urbanización. Consecuentemente, el suelo no ordenado ${ }^{55}$ ha ido disminuyendo aunque no en la misma cantidad ya que la LEN, en 1991, reclasificó un número importante de hectáreas antes urbanizables. El diagnóstico territorial para la elaboración de las DOT lo anota claramente: (...) se observa en la revisión del planeamiento de los últimos años, una clasificación de suelo urbano sobredimensionada y una reducción significativa del suelo urbanizable sin planeamiento parcial. (DOT-Diagnòstic, 1997:196).

La escondida labor de los planes de los 80 y 90 ha consistido en desplazar hacia el urbano gran cantidad de suelo que, junto al planeamiento parcial que se ha ido aprobando, sitúa el listón, sólo en suelo ordenado, a un nivel tres veces superior al del parque construido. El urbano es, sin duda, la gran reserva blindada para futuras expansiones inmobiliarias.

Como se hiciera con el sector turístico, en 1998 se han adoptado medidas de moratoria también urbanística que afectan, no lo olvidemos,

53 Terminología que, considerando que «el SNU no tiene orden», se refiere a los sectores urbanizables sin plan parcial aprobado.

$$
-432-
$$


únicamente al suelo urbanizable. La primera la tomó el Consell Insular de Mallorca sobre un centenar de sectores urbanizables finalmente rebajada a 77; la segunda se aprobó por ley a instancias del Gobierno Balear y afecta a todos los urbanizables residenciales que se encuentren fuera de plazos ${ }^{54}$. Ambas medidas se presentan como preventivas hasta que el futuro PTP, para Mallorca, y las DOT, para toda la comunidad, establezcan con carácter definitivo los techos urbanísticos de crecimiento.

La LGT y las DOT ¿el final de una primera etapa?-La aprobación por el Parlamento Balear en marzo de 1999, con apenas catorce días de diferencia, de la Ley General Turística (LGT) ${ }^{55}$ y las Directrices de Ordenación Territorial (DOT) ${ }^{56}$, parece que van a marcar un cambio de rumbo en cuanto a las reglas imperantes en la construcción del territorio. No cambia el móvil, que sigue siendo el crecimiento, sino la metodología para alcanzarlo. Efectivamente, lejos de parar las expectativas de crecimiento, la LGT y las DOT, reconducen y ponen orden en la incontrolada forma de generar territorio que se venía siguiendo.

La primera en ser aprobada por el Parlamento (16-3-1999) fue la LGT que, bajo la pretensión de unificar en un solo cuerpo la dispersa legislación turística de la comunidad, ahonda sobre todo en la reglamentación de las instalaciones hoteleras. De ahí que se le haya acusado de ser sectorial en el seno de un sector que, como el turístico, trasciende más allá de lo estrictamente hotelero.

La LGT mantiene, en línea con la transitoria Ley 4/1998, el requisito de aportar plazas de baja turística para obtener autorizaciones para otras de nueva creación ${ }^{57}$. La novedad con respecto a la 4/1998 es que ahora el canje de autorizaciones debe realizarse en el seno de cada isla cerrándose la posibilidad de intercambio interinsular. Está por ver el efecto que sobre el peso y función de las diferentes zonas turísticas puede tener esta

${ }^{54}$ Ley 6/1998, de 23 de octubre, de medidas cautelares hasta la aprobación de las Directrices de Ordenación Territorial. (BOCAIB de 24 de octubre de 1998.)

${ }_{55}^{5}$ Ley 2/1999, de 24 de marzo, General Turística de las Islas Baleares (BOCAIB de 1 de abril de 1999).

${ }_{56}$ Ley 6/1999, de las Directrices de Ordenación Territorial de las Islas Baleares y de medidas tributarias (BOCAIB de 17 de abril de 1999).

${ }_{57}$ El sistema sigue siendo el mismo que establecía la Ley 4/1998 que, recordémoslo, coincidía a su vez con lo regulado en el artículo 20 del POOT-Mallorca en el cual las 100 primeras plazas valen por 2 , las 100 segundas por 1,75 , las 100 terceras por 1,5 y sólo en las que excedan de 300 se equiparan las dadas de baja con las solicitadas de alta. Unos coeficientes que ahora pueden aumentarse en un $50 \%$ si la propiedad opta por ceder el viejo solar para espacio libre público. 
medida. En efecto, al «liberar» las autorizaciones de su localización puede generarse un flujo de plazas obsoletas hacia zonas turísticas que ofrezcan mejores expectativas con lo que el desajuste entre zonas está servido. La tendencia a la desturistización de unas zonas frente a la pujanza de otras puede ser el efecto más importante de esta medida.

Un segundo problema derivado del mecanismo de reconversión es saber donde se «compran» las autorizaciones obsoletas para intercambiar por otras nuevas, si en el mercado «libre» (aunque prácticamente cerrado desde 1998) o en una bolsa de plazas oficial, nutrida de las bajas voluntarias y forzosas, a la que deberían acudir los interesados en abrir nuevas instalaciones de alojamiento turístico. Al final se opta por la «posibilidad» de creación de un organismo que, integrado por hoteleros, administración y cajas de ahorro, gestione, por islas, la bolsa de plazas a la que «podrán» acudir los interesados. Se abre, por tanto, la posibilidad de reventa en el mercado «libre sin competencia» de las autorizaciones ya amortizadas ${ }^{58}$.

Una tercera cuestión a resolver era la planteada con el uso a que debía ser destinado el solar y la edificación que se dan de baja como consecuencia del intercambio. Ahí el abanico de posibilidades iba desde la demolición y destino a equipamiento público hasta la libre reconversión del edificio dado de baja turística. Finalmente el paso a equipamiento únicamente se asegura si el planeamiento municipal así lo prevé, con lo cual sólo en contadísimas ocasiones se conseguirá equipar las zonas turísticas con los solares y edificios obsoletos que se hayan intercambiado. La LGT modifica el POOT a la baja para dar más facilidades a la reconversión residencial de los solares y edificios dados de baja turística.

Por último era interesante ver como respondía la LGT a las nuevas modalidades emergentes en el tercer boom turístico: viviendas vacacionales, turismo rural, «time sharing», etc. En cuanto a las primeras sólo se les exige que se acojan a los mecanismos de intercambio si hay más de tres viviendas contiguas en un mismo núcleo de población, con ello se escapan al sistema todas las existentes en rústico. Para modalidades como turismo rural o «time sharing» la LGT se remite a sus regulaciones específicas.

58 Según informaciones aparecidas en la prensa local el precio de las primeras operaciones de venta privada de autorizaciones de plazas obsoletas puede oscilar, según los casos, entre las 300.000 y el 1.000 .000 de pesetas por plaza. 
Como se ve la LGT regula y ordena los productos más emblemáticos del primer y segundo boom turísticos mientras que saca de la regla a los productos típicos del tercero. Apartamentos adquiridos en propiedad o alquilados según la Ley de arrendamientos urbanos y «time sharing» cabrán perfectamente en los edificios y solares que la oferta obsoleta, una vez revendida y reconvertidas para su emigración a otros destinos insulares, vaya generando. El cuerpo del primer y segundo boom turístico (hoteles y apartamentos obsoletos) se reconvierte a la moda del tercer boom, mientras el alma (autorizaciones turísticas) puede volar «libremente» - con algún complemento adicional para aligerar el viaje- hacia destinos modernizados. Seguramente habrá que esperar al cuarto boom turístico para que se regule el tercero.

Apenas catorce días después de aprobarse la LGT (30-3-1999) el Parlamento aprobó, como dijimos, las Directrices de Ordenación Territorial (DOT). Planteadas y anunciadas como la Constitución del territorio, las DOT no han conseguido el consenso necesario que les hubiera hecho merecedoras de tal calificación. Las DOT son, en realidad, unas medidas de ordenación y encauzamiento de unos ritmos de crecimientos que, como veremos, no se limitan en absoluto. Sin embargo, como ley marco que es, establece los planes sectoriales y territoriales de desarrollo que deberán realizarse al tiempo que crea el instrumento de las llamadas Áreas de Reconversión Territorial para la reconversión y mejora de los armazones territoriales existentes. Por lo demás, las DOT consolidan el modelo territorial vigente y dan carta legal a un esquema que, si bien hasta ahora no era explícito, se halla implícito en la aplicación combinada de los instrumentos municipales de ordenación urbanística.

Las medidas más emblemáticas de las DOT consisten en la prohibición de creación de nuevos núcleos urbanizables aislados, así como en los primeros 500 metros desde la ribera de mar ${ }^{59}$. Al mismo tiempo se limita la clasificación de urbanizable al interior de una orla periurbana de $500 \mathrm{~m}$ de los núcleos existentes.

El dimensionado del crecimiento potencial del alojamiento - sobre los 3,6 millones de población potencial del suelo ordenado- se cuan-

59 En realidad esta prohibición es reiterativa respecto a lo dispuesto en la LEN (art. 7) y en los POOT (art. 14). La novedad de la medida, además del superior rango legal que suponen las DOT, reside en la inedificabilidad de los suelos rústicos protegidos en esta banda. Una banda que se reduce a $250 \mathrm{~m} a$ ) en suelo rústico común.

$$
-435-
$$


tifica en un 10\% (12\% en Menorca) en un horizonte temporal de diez años. Este porcentaje se calcula sobre la superficie del suelo urbano y urbanizable con aprobación definitiva en el momento de la entrada en vigor de las DOT (18-4-1999). A las hectáreas resultantes para cada isla se les asigna un aprovechamiento equivalente de 100 hab./Ha. Las tres bolsas insulares serán repartidas intermunicipalmente por los tres futuros Planes Territoriales Parciales a partir de criterios que priman los términos municipales menos desarrollados urbanísticamente frente a los más desarrollados. Tal reparto intermunicipal del nuevo crecimiento sólo puede ubicarse en el interior de las orlas periurbanas antes citadas.

Este «nuevo crecimiento» se ha evaluado en un equivalente a unas 200.000 plazas (turísticas o no) a sumar a las ya «ordenadas» en suelo urbano ( 3,5 millones) y suelo rústico $(0,5$ millones), con lo cual nos encontramos, nuevamente, ante la vieja táctica de evitar la planificación efectiva por sobreelevación del listón del techo de población ordenable (4,2 millones de habitantes) sobre la capacidad de habitación construida (1,5 millones).

La reducción del suelo urbanizable que suponen, en Mallorca, las DOT reemplaza parcialmente la que pretendía llevar a cabo la antes mencionada moratoria urbanística del Consell Insular de Mallorca. Sin embargo, mientras aquella afecta especialmente a los contornos urbanizables de los núcleos urbanos de interior, la del Consell de Mallorca afectaba con mayor contundencia a los sectores urbanizables del litoral.

La limitación del nuevo desarrollo urbano al interior de la orla de los primeros $500 \mathrm{~m}$ periurbanos, puede acarrear mayores problemas de los que seguramente inicialmente se han previsto. En este sentido basta recordar como la estructura de la propiedad en las inmediaciones de las poblaciones es extremadamente minifundista, especialmente en los núcleos tradiciones de interior, no ocurre así en los núcleos turísticos costeros que normalmente se han desarrollado sobre grandes propiedades de «marina». La dificultad de desarrollar urbanizables sobre estructuras de la propiedad munifundista — con los sistemas de actuación vigentes actualmente- es más que conocida ${ }^{60}$. Incluso dónde este minifundismo no existe (núcleos costeros), tanto el POOT como las propias

${ }^{60}$ No obstante se ha anunciado que la futura Ley del Suelo Balear regulará, en línea con la legislación valenciana, la figura del urbanizador (Huguet, Aguiló y Bonilla, 1997:674) que, de tener los mismos efectos que ha tenido en la Comunidad Valenciana, podrá desatascar gran parte de la oferta ahora enredada en problemas de gestión. 
DOT imposibilitan tal desarrollo. Los núcleos de interior de Mallorca presentan una clara estructura minifundista en las orlas que los envuelven (Fig. 4). Dicha estructura dificultará el desarrollo del urbanizable que las DOT prevén en los primeros $500 \mathrm{~m}$. En cuanto al hábitat y parcelación, (Fig. 5) según Jean Bisson, 1977:152; tanto los modelos 2 (llano central) y 3 (sur) de Mallorca, como el 2 de Menorca (sur-este) y el Ibicenco, ofrecerán grandes resistencias al desarrollo urbano diseñado por las DOT. El modelo 1 (montaña) de Mallorca y el 1 (norte y sur central) de Menorca verán reducidas sus posibilidades de desarrollo debido a las disposiciones de la LEN. De ahí que es más que previsible que el nuevo crecimiento siga la senda del suelo edificable vacante y del rústico más que el del suelo urbanizable, una clase de suelo muy satanizada en las Islas Baleares después de la experiencia urbanística de la segunda mitad del siglo xx. Muerto el suelo urbanizable, el urbano y el rústico cogerán el testigo de la segunda etapa de crecimiento que la LGT y las DOT pretenden inaugurar.

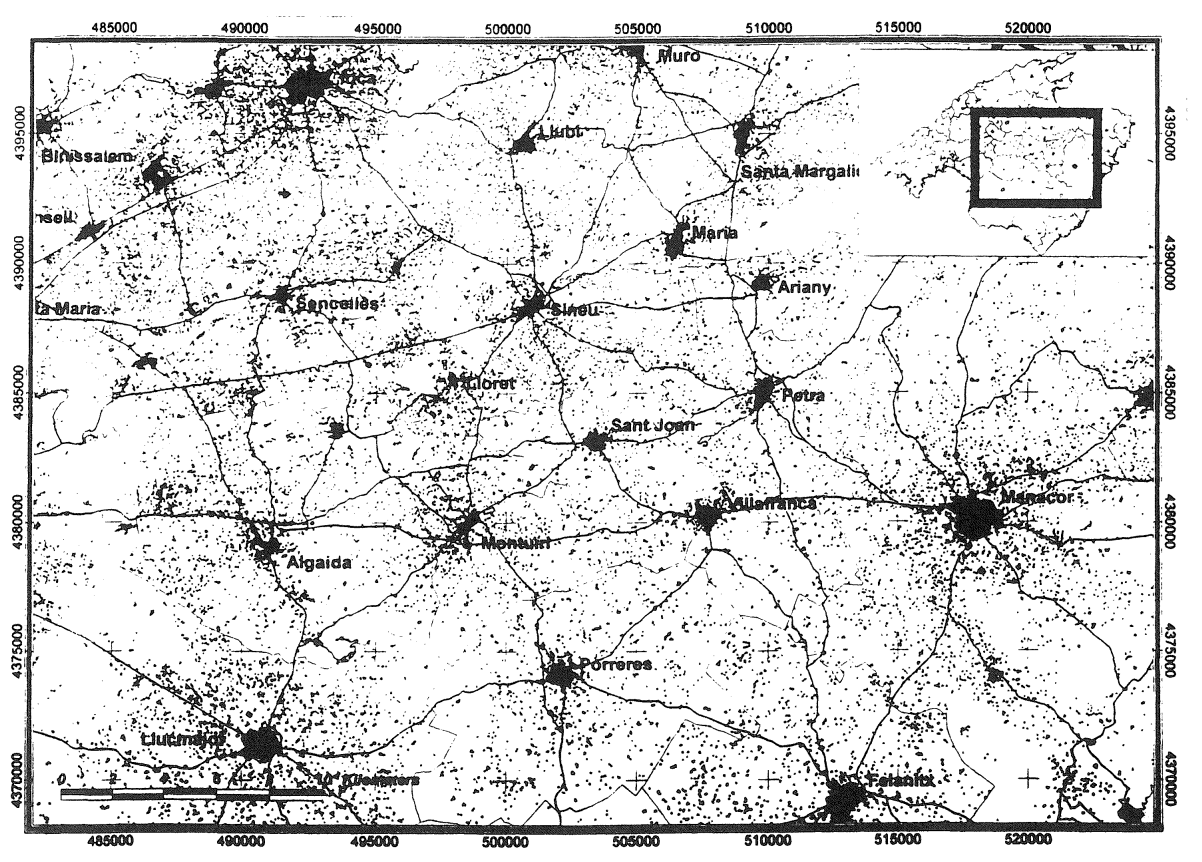

FIG. 4.-El minifundismo de las orlas periurbanas de interior. 


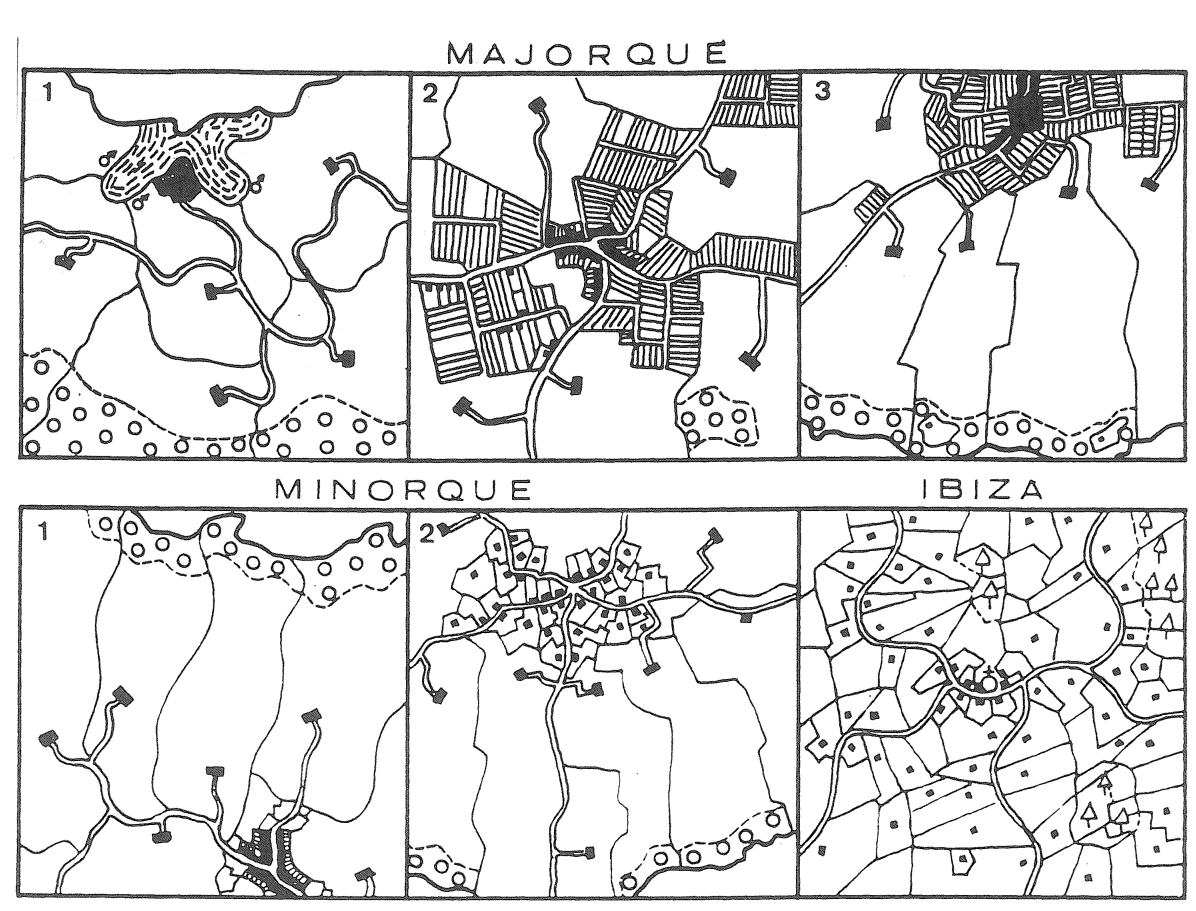

FIG. 5.-Modelos de asentamiento tradicional en las Baleares (según Bisson).

\section{Tendencias, conclusiones y discusión}

La fuerte pendiente de expansión edificatoria que experimentan las Islas Baleares al final del segundo milenio se basa, como en épocas anteriores, en una importante tasa de crecimiento turístico que ahora acoge nuevas modalidades de carácter más residencial. Tal tendencia afecta a todo el territorio, a todas las clases de suelo. La venta de parte del parque residencial construido a ciudadanos comunitarios va precisamente en esta línea expansiva y de emergencia de nuevas modalidades. De ahí que el sector inmobiliario esté creciendo por encima de lo que lo hace el estrictamente turístico y muchísimo más de lo que la demanda local requeriría.

Las medidas que se aplican para controlar el proceso son, como en otros momentos de fuertes acelerones de crecimiento, tenues y de 
efectividad relativa. Al limitar muy por encima de las expectativas, de hecho, no se limita. La demanda tiene el campo libre para desarrollarse sin ningún tipo de contención cuantitativa aunque la localización del nuevo crecimiento, con las DOT, ya no es tan «libre» como antes. Ahora sólo las orlas periurbanas podrán acoger el nuevo desarrollo urbano. En este contexto la dispersión de la residencia sobre todos los paisajes insulares y la edificación en suelo vacante (urbano y urbanizable ordenado), es la tónica dominante que caracterizan el fin de siglo y milenio.

La capacidad de alojamiento construido (1,5 millones de habitantes frente a los 0,7 millones de residentes) sitúa el archipiélago sobre cotas de densidad centroeuropeas (por encima de los $300 \mathrm{hab} . / \mathrm{km}^{2}$ ) que, en momentos punta de temporadas alta, hacen saltar las alarmas de todos los sectores y agentes sociales. La capacidad construible después de las DOT según todos los tipos de planes (4,2 millones) nos sitúa en una densidad urbanística potencial superior a los $800 \mathrm{hab} . / \mathrm{km}^{2}$.

La densidad medida en hab./ $\mathrm{km}^{2}$, se nos presenta como el indicador de confortabilidad territorial y, por lo tanto, de sostenibilidad turística más fiable una vez superados técnicamente los clásicos factores limitativos de carácter natural (agua, energía, suelo agrícola) ${ }^{61}$. Los más de 300 hab. $/ \mathrm{km}^{2}$ suponen unos niveles de «hacinamiento territorial» equivalentes a una disponibilidad media de poco más de $3.000 \mathrm{~m}^{2} / \mathrm{hab}$. que, de consumarse las potencialidades de los planes se verían reducidos a poco más de 1.000 .

Para reducir la densidad o, lo que es lo mismo, aumentar la disponibilidad media de territorio por habitante, puede actuarse sobre el numerador - habitantes - o sobre el denominador - $\mathrm{km}^{2}-$. Las apuestas de actuación sobre el número de habitantes son, como hemos podido comprobar, siempre al alza: más plazas, más residencias, menos estacionalidad, más modalidades turísticas, etc. Por su parte las actuaciones sobre el denominador - $\mathrm{km}^{2}$ — son a la baja. Efectivamente la política de carreteras tiende inexorablemente a acortar distancias, con lo cual las islas encogen y se contraen y, al disminuir el denominador relativo, aumenta la densidad.

${ }^{61}$ La no limitación de tales factores debe entenderse a escala balear y dados los niveles actuales de renta. Analizando la situación a escalas más generales - cuenca mediterránea o, incluso, planeta tierra - no está garantizada a medio-largo plazo con los actuales niveles de crecimiento y consumo. 
Las Islas Baleares se enfrentan a una coyuntura que, ante las mayores cotas conocidas de crecimiento de la historia, las políticas que se implementan tienden a aumentar el denominador - habitantes potenciales-y disminuir el numerador - reducción de distancias por efecto de las grandes infraestructuras de carreteras - con lo cual la tendencia claramente perceptible para principios del tercer milenio es el aumento vertiginoso de la densidad. Un aumento por encima de los límites más prudentes de sostenibilidad —medida en términos de confortabilidad territorial- durante períodos de tiempo cada vez más largos.

\section{BIBLIOGRAFÍA}

Aguiló, E.; Bardolet, E. y SAstre, A. (1981): El turismo en las Baleares, CGI/CEH/Banca March, $158 \mathrm{pp}$.

Aguiló, E. y Verger, A. (1982): El urbanismo y el medio ambiente en las Baleares, Palma, CGI/CEH/Banca March, 115 pp.

Aguiló PÉRez, E. (1998): «Política turística». In J. Mella Márquez (Ed.), Economía y política regional en España ante la Europa del Siglo XXI, Madrid, Akal, 445-460.

AlBertí SASTRE, A. (1995): Mercat turístic Balear, Palma, Institut d'Estudis Baleàrics, 144 $\mathrm{pp}$.

BARCEló Pons, B. (1989): «Aigua i turisme a les Illes Balears». In Libro jubilar dedicado al profesor Antonio López Gómez, Valencia, Universitat de València/Universidad de Alicante, 303-314.

BARDOLEt, E. (1999, 30-1-1999): Las pernoctaciones turísticas en Baleares en 1997. Última Hora, pág. 30.

Bisson, J. (1977): La terre et l'homme aux îles Baleares, Aix-en-Provence, EDISUD, $416 \mathrm{pp}$.

Blasco, A. (1996): Legislació d'ordenació del territori i urbanisme de les Illes Balears, Palma, UIB, 434 pp.

Blasco, A. y Segura, F. (1994): Legislación turística estatal y balear, Palma, UIB-GBFEHM, 599 pp.

CGI (1982): Propuesta de modificación del Plan Provincial de Ordenación de Baleares, Palma, Consell General Interinsular. Conselleria d'Ordenació del Territori, 27 pp.

Cladera Cladera, J. (1993): «La reconversión de las zonas turísticas saturadas. El caso de Baleares», La formació, la rehabilitació $i$ les noves modalitats turístiques, Palma, UIB-CODEFOC-EUROFORUM-AGE, 65-69.

Cruz Mera, A. (1997): «La legislación estatal y autonómica en materia de urbanismo. Un repaso a la legislación sobre ordenación del territorio», Ciudad y Territorio. Estudios Territoriales, . $^{\circ} 113-114,589-599$.

DOT-Diagnòstic (1997): Directrius d'Ordenació Territorial. Anàlisi i Diagnòstic, Palma, Govern Balear, 244 pp.

EvoluCIÓN ECONÓMICA (1973-1997): Serie publicada por Banca Catalana-Caixa de les Balears. Palma.

FERnÁNDEZ DuRán, R. (1993): La explosión del desorden. La metrópoli como espacio de la crisis global, Ed. Fundamentos, 412 pp.

Gravagnuolo, B. (1998): Historia del urbanismo en Europa, 1750-1960, Madrid, Akal ediciones, 486 pp. 
Huguet, C.; Aguiló, P. y Bonilla, J. (1997): «Consecuencias de la Sentencia del Tribunal Constitucional 61/97 en la situación urbanística de la Comunidad Autónoma de las Islas Baleares», Ciudad y Territorio. Estudios Territoriales, n. ${ }^{\circ} 113-114,667-674$.

LBTB (1987): Llibre Blanc del Turisme a les Balears, Palma, Conselleria de Turisme-Caixade les Balears- Universitat de les Illes Balears, $448+381$ pp.

López Casasnovas, G. y Rosselló Villalonga, J. (1998): 25 anys. Evolució econòmica de Balears, Barcelona, Banca Catalana-Caixa de Balears, 118 pp.

PICORNELl BAUZÀ, C. (1985): «La problemàtica territorial a les Illes Balears», Lluc, n. ${ }^{\circ} 722$, 14-23.

PPOB (1970): Plan Provincial de Ordenación de Baleares. Documentación informativa. Memoria, Palma, Diputación Provincial de Baleares, 400 pp.

RAMIS RAmos, A. (1998): Regulación administrativa y parámetros urbanísticos en la legislación turística estatal y balear, Palma, Col-legi Oficial d'Arquitetes de Balears, $111 \mathrm{pp}$.

Reig Martínez, E. y Picazo TAdeo, A. J. (1998): Capitalización y crecimiento de la economía balear 1955-1996, Madrid, Fundación BBV. Documenta, 320 pp.

Rivero Ceballos, J. L. y Salvá i Tomás, P. A. (1998): «La evolución dinámica de los archipiélagos». In J. M. Mella Márquez (Ed.), Economía y política regional en España ante la Europa del siglo XXI, Madrid, Akal Ediciones, 206-207.

RULLAN, O.; MANCHADO, J. y MARCús, A. (1998): «La captación del gradiente residencial en suelo rústico. Una propuesta metodológica ensayada en las Islas Baleares», Ciudad y Territorio. Estudios Territoriales, n. ${ }^{\circ} 115,125-144$.

Rullan Salamanca, O. (1989a): «Estructuras territoriales planificadas estudiadas mediante análisis multivariado», Norba. Geografia , n. ${ }^{\circ}$ VIII-IX, 623-638.

Rullan SAlAmAnCA, O. (1989b): «La previsió de sòl a Mallorca. Una variable condicionada pel turisme i la segona residència», Treballs de Geografia, n. ${ }^{\circ} 42,119-128$.

RULLAN SALAMANCA, O. (1995a): «Legislación balear versus territorio y medio ambiente». In A. Vila y J. L. Pujol (Ed.), Turismo y territorio, Palma, COAB, 153-178.

RULlan SALAMANCA, O. (1995b): «Técnicas instrumentales y planeamiento para los años noventa». In Grupo de G. ${ }^{a}$ Urbana-AGE (Ed.), Las ciudades españolas a finales del siglo Xx, Cuenca, Asociación de Geógrafos Españoles (AGE), 179-198.

Rullan SAlamanca, O. (1997): «De la cova de Canet al tercer boom turístic. Una primera aproximació a la geografia històrica de Mallorca». Ponencia presentada a El medi ambient a les Illes Balears. Qui és qui?, Palma, en prensa.

Seguí RAmón, J. (1998): Les Balears en venda. La desinversió inmobiliària dels illencs, Palma, Documenta Balear, $241 \mathrm{pp}$.

Socías CAMACHO, J. M. (1998): «Evolución de la legislación turística en las islas Baleares», Revista Aragonesa de Administración Pública, n. ${ }^{\circ} 13,197-234$.

Terán Troyano, F. DE (1982): Planeamiento urbano en la España contemporánea (1900-1980), Madrid, Alianza Editorial, 631 pp.

Terán Troyano, F. DE (1996): «Evolución del planeamiento urbanístico (1846-1996)», Ciudad y Territorio. Estudios Territoriales, n. ${ }^{\circ} 107-108,167-184$.

Vera Rebollo, F. (1990): «El auge de la promoción inmobiliaria en la franja litoral alicantina y sus efectos en la reestructuración de la oferta», Treballs de Geografía, n. ${ }^{\circ} 43,49-57$.

RESUMEN: Crecimiento y política territorial en las Islas Baleares (1955-2000). Las Islas Baleares han experimentado, en la segunda mitad del siglo xx, una profunda transformación económica y territorial de la mano del turismo. Tres fases son claramente diferenciables en el proceso, la frontera entre la primera y la segunda se establece a partir de la crisis de 1973, mientras que la segunda y la tercera se desligan, en la primera mitad de los 90 , a partir de la efectiva integración en la economía europea. 
Las tres pulsaciones de crecimiento son abordadas por políticas territoriales estatales o autonómicas (a partir de 1983) que llegan periódicamente tarde para encauzar los expansivos crecimientos de cada período. El último producto de las políticas territoriales baleares lo constituye la Ley General Turística y las Directrices de Ordenación Territorial de 1999 que, sin parar el crecimiento, lo ordenan en el espacio y en el tiempo. Tales disposiciones parecen marcar el final de una primera etapa que, desarrollada en tres fases, se inició a mediados de los años 50.

El presente artículo analiza el proceso seguido al tiempo que intenta plantear el posible escenario que las tendencias parecen marcar.

Palabras Clave: Islas Baleares, turismo, urbanismo, ordenación del territorio, ordenación turística.

ABSTRACT: Growth and land-use policy in the Balearic Islands (1955-2000). In the second half of the twentieth century the Balearic Islands have experienced a profound economic and physiognomic transformation at the hands of tourism. Three phases can be clearly differentiated in the process; the boundary between the first and the second is the crisis of 1973, while the second and the third are divided by Spain's effective integration into the European economy, in the irst half of the $90 \mathrm{~s}$.

The three pulses of growth have been addressed by national or autonomous community (since 1983) land-use policies that have periodically arrive too late to channel the expansive growth of each period. The latest products of Balearic land-use policies are the General Tourism Law (Ley General Turistica) and the 1999 Regional Planning Directives (Directrices de Ordenación Territorial), which do not stop growth but do order it in space and time. Such ordinances seem to mark the end of a first stage, which has unfolded in three phases beginning in the middle of the $50 \mathrm{~s}$.

This article analyses the process and attempts to lay out the possible scenario to which the prevailing tendencies seem to point.

KEYWORDS: Balearic Islands, tourism, urban planning, regional planning, tourism planning.

RÉSumÉ: Croissance et politique territoriale aux Iles Baléares (1955-2000). Les Iles Baléares ont connu, dans la seconde moitié du $\mathrm{XX}^{\mathrm{e}}$ siècle, une transformation économique et territoriale profonde due au tourisme. Dans ce processus, on peut distinguer clairement trois phasses, la crise de 1973 marquant la frontière entre la première et la deuxième, et l'intégration effective au sein de l'économie européenne provoquant la scission entre la deuxième et la troisième.

Ces trois poussées de coissance sont abordés par des politiques territoriales d'Etat ou des politiques autonomiques (á partir de 1983) qui arrivent régulièrement tard pour canaliser ce phénomène de croissance expansive de chacune de ces périodes. Le dernier produit des politiques territoriales aux Baléares est la Ley General Turística et les Directrices de Ordenación Territorial de 1999 (Loi générale sur le Tourisme et Directives relatives á l'Aménagement du territoire), lesquelles visent á un aménagement dans l'espace et dans le temps sans toutefois mettre un terme á la croissance. Ces dispositions semblent marquer la fin d'une première étape, qui s'est développée en trois phases et dont l'origine remonte au milieu des années 50.

Le présent article analyse le dit processus au temps qu'il essaie d'envisager le cadre que les tendances semblent déterminer.

Mots-CLÉ: Iles Baléares, tourisme, urbanisme, aménagement du territoire, amémagement touristique. 